\title{
Coordinated Postnatal Maturation of Striatal Cholinergic Interneurons and Dopamine Release Dynamics in Mice
}

\author{
Avery F. McGuirt, ${ }^{1}$ Michael R. Post, ${ }^{1}$ Irena Pigulevskiy, ${ }^{1}{ }^{\circledR}$ David Sulzer, ${ }^{1,2}$ and ${ }^{\circledR}$ Ori J. Lieberman ${ }^{1}$ \\ ${ }^{1}$ Departments of Psychiatry, Neurology, Pharmacology, Columbia University Irving Medical Center, New York, New York 10032, and ${ }^{2}$ Division of \\ Molecular Therapeutics, New York State Psychiatric Institute, New York, New York 10032
}

\begin{abstract}
Dynamic changes in motor abilities and motivated behaviors occur during the juvenile and adolescent periods. The striatum is a subcortical nucleus critical to action selection, motor learning, and reward processing. Its tonically active cholinergic interneuron (ChI) is an integral regulator of the synaptic activity of other striatal neurons, as well as afferent axonal projections of midbrain dopamine (DA) neurons; however, little is known about its development. Here, we report that ChI spontaneous activity increases during postnatal development of male and female mice, concomitant with a decreased afterhyperpolarization (AHP). We characterized the postnatal development of four currents that contribute to the spontaneous firing rate of ChIs, including $\mathrm{I}_{\mathrm{SK}}, \mathrm{I}_{\mathrm{A}}, \mathrm{I}_{\mathrm{h}}$, and $\mathrm{I}_{\mathrm{NaP}}$. We demonstrated that the developmental increase in $\mathrm{I}_{\mathrm{NaP}}$ drives increased $\mathrm{ChI}$ firing rates during the postnatal period and can be reversed by the $\mathrm{I}_{\mathrm{NaP}}$ inhibitor, ranolazine. We next addressed whether immature cholinergic signaling may lead to functional differences in DA release during the juvenile period. In the adult striatum, nicotinic acetylcholine receptors (nAChRs) prevent linear summation of DA release in response to trains of high-frequency stimuli. We show that, in contrast, during the second postnatal week, DA release linearly sums with trains of high-frequency stimuli. Consistently, nAChR antagonists exert little effect on dopamine release at postnatal day (P)10, but enhance the summation of evoked DA release in mice older than postnatal day P28. Together, these results reveal that postnatal maturation of $\mathrm{ChI}$ activity is due primarily to enhanced $\mathrm{I}_{\mathrm{NaP}}$ and identify an interaction between developing cholinergic signaling and DA neurotransmission in the juvenile striatum.
\end{abstract}

Key words: action selection; basal ganglia; cholinergic interneuron; development; dopamine; striatum

Significance Statement

Motor skills and motivated behavior develop rapidly in juvenile rodents. Recent work has highlighted processes that contribute to the postnatal maturation of striatal principal neurons during development. The functional development of the striatal cholinergic interneuron (ChI), however, has been unexplored. In this study, we tracked the ontogeny of ChI activity and cellular morphology, as well as the developmental trajectory of specific conductances that contribute to the activity of these cells. We further report a link between cholinergic signaling and dopamine (DA) release, revealing a change in the frequency-dependence of DA release during the early postnatal period that is mediated by cholinergic signaling. This study provides evidence that striatal microcircuits are dynamic during the postnatal period and that they undergo coordinated maturation.

Received Apr. 1, 2020; revised Feb. 24, 2021; accepted Feb. 26, 2021.

Author contributions: A.F.M., D.S., and 0.J.L. designed research; A.F.M., M.R.P., I.P., and 0.J.L. performed research; I.P. contributed unpublished reagents/analytic tools; A.F.M., M.R.P., and 0.J.L. analyzed data; 0.J.L. wrote the paper.

This work was supported by National Institute of Mental Health Grants 3T32NS064928-09 (to A.F.M.), 5F30MH114390-02 (to 0.J.L.), and 5T32MH020004 and K99MH122659 (to M.R.P.) and by the National Institutes of Health National Institute on Drug Abuse Grant R01DA007418, the Simons Foundation Grant SFARI 514813, and the JPB Foundation (to D.S.). We thank Sejoon Choi for technical guidance and generous training on electrophysiology technique; Eugene Mosharov, who developed the cyclic voltammetry acquisition and analysis software and provided further advice and technical support; and an anonymous referee of the manuscript for advice to focus on the persistent sodium current.

The authors declare no competing financial interests.

Correspondence should be addressed to Ori J. Lieberman at 0j12106@cumc.columbia.edu or David Sulzer at ds43@cumc.columbia.edu.

https://doi.org/10.1523/JNEUROSCI.0755-20.2021

Copyright $\odot 2021$ the authors

\section{Introduction}

The early postnatal period is a time of extraordinary development of sensorimotor abilities (Altman and Sudarshan, 1975; Shaywitz et al., 1979; Westerga and Gramsbergen, 1990). In rodents, locomotor activity increases dramatically during the second postnatal week (Altman and Sudarshan, 1975; Shaywitz et al., 1979; Westerga and Gramsbergen, 1990; Doremus-Fitzwater et al., 2012; Spear, 2013), including increased exploration and acquisition of motivated behaviors that integrate internal and external states (Hall et al., 1977).

The striatum is the main input nucleus of the basal ganglia and contributes to action selection, motor learning, and motivated behaviors in the adult (Gerfen and Surmeier, 2011). The cholinergic interneuron (ChI) comprises only 
$\sim 1-5 \%$ of striatal neurons (Kemp and Powell, 1971a,b), but because of its widespread axonal arborization and synaptic connections with other striatal neurons, acts as a critical node in striatal synaptic computation (DiFiglia et al., 1976; DiFiglia, 1987; Kawaguchi, 1993; Aosaki et al., 1994a,b; Matsumoto et al., 2001; Reynolds et al., 2004; Goldberg and Reynolds, 2011; Goldberg et al., 2012). Additionally, dopamine (DA) axons innervating the striatum express nicotinic acetylcholine receptors (nAChRs), through which ChIs regulate DA release during motivated behaviors (Le Novère et al., 1996; Azam et al., 2002; Zoli et al., 2002; Exley and Cragg, 2008; Cachope et al., 2012; Threlfell et al., 2012; Sulzer et al., 2016; Mohebi et al., 2019).

ChIs are tonic pace-making neurons with spontaneous firing frequencies between 2 and $10 \mathrm{~Hz}$ (Wilson et al., 1990; Bennett and Wilson, 1999). In the adult, spontaneous ChI activity is driven by intrinsic ion conductances that are independent of synaptic input (Bennett et al., 2000). $\mathrm{I}_{\mathrm{h}}$, the current mediated by hyperpolarization-activated cyclic nucleotide-gated (HCN) channels, depolarizes ChIs to $-60 \mathrm{mV}$, where these channels inactivate. A persistent sodium current $\left(\mathrm{I}_{\mathrm{NaP}}\right)$ then drives the cell to its action potential threshold, where $\mathrm{Ca}_{\mathrm{V}} 2$ calcium channels open (Bennett et al., 2000). After the cell fires, SK and BK calcium-activated potassium channels repolarize the cell and control the magnitude of a potential change known as the medium afterhyperpolarization (mAHP; Goldberg and Wilson, 2005).

Given the postnatal acquisition of motivated behavior and mature motor activity, and the importance of ChIs in these processes in adulthood, we investigated whether ChI activity and cholinergic control over DA release undergo maturational changes during the juvenile period. To address these questions, we performed cell-attached and whole-cell recordings of ChIs in the dorsal striatum of acute brain slices from mice over a range of ages. We found that the spontaneous activity of ChIs increases linearly from postnatal day (P)10 into adulthood, and that this is driven by an increase in the $\mathrm{I}_{\mathrm{NaP}}$ current over this same period. This developmental change was accompanied, during an early phase between P14 and P18, by a reduction in the mAHP. Then, using fast-scan cyclic voltammetry (FSCV), we characterized DA release properties in the juvenile striatum, demonstrating the absence of nAChR-mediated modulation of DA release at P10. These data suggest that the functionality of ChIs and ACh-DA interactions in striatal information processing are acquired postnatally. Along with maturation of the principal striatal neurons (spiny projection neurons; SPNs) and inhibitory interneurons that occur during this period (Surmeier et al., 1991; Choi and Lovinger, 1997; Tepper et al., 1998; Plotkin et al., 2005; Gertler et al., 2008; Cazorla et al., 2012; Kozorovitskiy et al., 2012, 2015; Peixoto et al., 2016; Lieberman et al., 2018; Krajeski et al., 2019; Kuo and Liu, 2019), these data suggest that the striatum is remarkably dynamic during postnatal maturation, likely
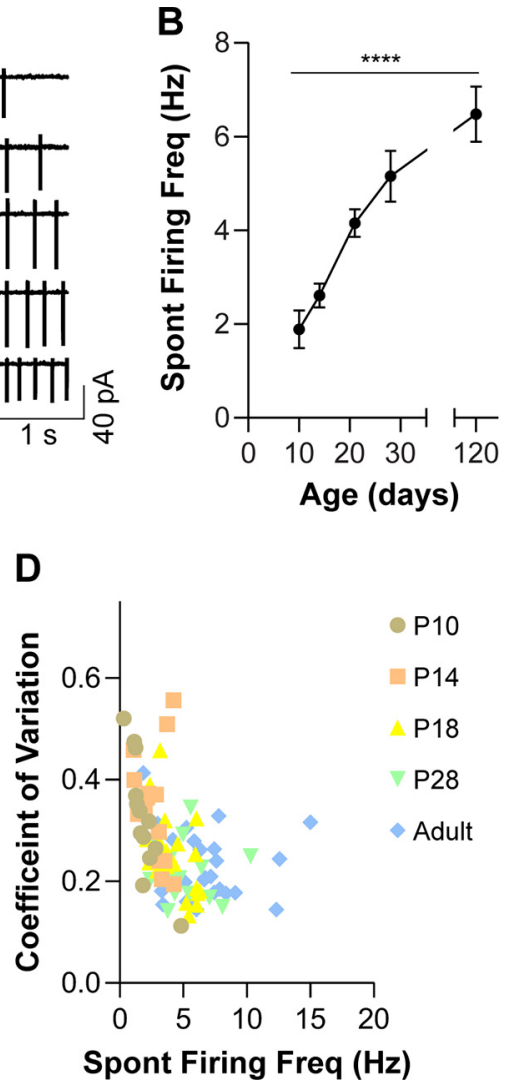

\section{Spont Firing Freq $(\mathrm{Hz})$}

Figure 1. Postnatal maturation of spontaneous $\mathrm{Chl}$ activity. A, Sample cell-attached recordings from Chls at P10, P14, P18, P28, and adults (P110-P120). B, A significant increase in Chl spontaneous firing frequency from P10 to adulthood. P10: $n=18$ cells (4 mice), P14: $n=16(2)$, P18: $n=23(4)$, P28: $n=15(3)$, adult: $n=28(6)$. N is the same in C, D. spontaneous firing frequency for each recorded cell. The ages of the cells are reported by color. $R^{2}=0.205 ; p<0.0001$ for all cells; $* * * * p<0.0001$. Data analyzed in $\boldsymbol{B}, \boldsymbol{C}$ with one-way ANOVA. Mean \pm SEM is shown.

facilitating the development of the complex repertoire of behaviors that depend on striatal circuitry.

\section{Materials and Methods}

Animals

C57Bl6J breeder pairs were obtained from The Jackson Laboratory. Transgenic Dat-Ires-Cre Ai38 mice were generated as described (Lieberman et al., 2017). Mice were housed in same-sex groups of two to four on a 12/12 h light/dark cycle with water and food available ad libitum. Breeding pairs were checked daily for pregnancy and new litters. Mice were used for experiments on the specified postnatal day $( \pm 1)$ in all experiments. All experimental procedures were approved by the Columbia University Institutional Animal Care and Use Committee and followed guidelines established in the NIH Guide for the Care and Use of Laboratory Animals. Data combine male and female mice, and no differences were observed between sexes.

\section{Electrophysiology}

Acute brain slices were generated as described previously (Lieberman et al., 2018, 2020). Mice underwent rapid cervical dislocation. The brain was placed in ice-cold cutting buffer: $10 \mathrm{~mm} \mathrm{NaCl}, 2.5 \mathrm{~mm} \mathrm{KCl,} 25 \mathrm{~mm}$ $\mathrm{NaHCO}_{3}, 0.5 \mathrm{~mm} \mathrm{CaCl}_{2}, 7 \mathrm{~mm} \mathrm{MgCl}, 1.25 \mathrm{~mm} \mathrm{NaH}_{2} \mathrm{PO}_{4}, 180 \mathrm{~mm}$ sucrose, and $10 \mathrm{~mm}$ glucose bubbled with $95 \% \mathrm{O}_{2} / 5 \% \mathrm{CO}_{2}$ to $\mathrm{pH}$ 7.4. Coronal slices $(250 \mu \mathrm{m})$ were generated using a Leica vibratome and placed in artificial CSF (ACSF) and allowed to rest at $34^{\circ} \mathrm{C}$ for $30 \mathrm{~min}$. The recipe for ACSF was: $125 \mathrm{~mm} \mathrm{NaCl}, 2.5 \mathrm{~mm} \mathrm{KCl}, 25 \mathrm{~mm} \mathrm{NaHCO}_{3}, 2$ $\mathrm{mm} \mathrm{CaCl}_{2}, 1 \mathrm{~mm} \mathrm{MgCl}, 1.25 \mathrm{~mm} \mathrm{NaH}_{2} \mathrm{PO}_{4}$ and $10 \mathrm{~mm}$ glucose bubbled with $95 \% \mathrm{O}_{2} / 5 \% \mathrm{CO}_{2}$ to $\mathrm{pH} 7.4$. Slices were then maintained at room temperature for a maximum of $5 \mathrm{~h}$ for recordings. 
Table 1. Passive membrane properties of Chls

\begin{tabular}{|c|c|c|c|c|c|c|}
\hline Parameter & $\mathrm{P} 10$ & P14 & P18 & $\mathrm{P} 28$ & $\mathrm{P} 120$ & Age effect ${ }^{5}$ \\
\hline Capacitance (pF) & $126.0 \pm 5.880(37)^{\#}$ & $150.4 \pm 15.73(16)$ & $148.9 \pm 15.6(25)$ & $128.1 \pm 7.190$ & $140.1 \pm 8.538(29)$ & $\begin{array}{l}F_{(4,140)}=1.283 \\
p=0.2785\end{array}$ \\
\hline Input resistance ( $\mathrm{M} \Omega$ ) & $306.9 \pm 21.13(37)$ & $275.6 \pm 9.032(16)$ & $219.4 \pm 14.69(25)$ & $172.3 \pm 9.377(38)$ & $202.8 \pm 10.88(29)$ & $\begin{array}{l}F_{(4,140)}=14.6 \\
p<0.0001\end{array}$ \\
\hline Tau (ms) & $36.68 \pm 2.248(38)$ & $40.67 \pm 3.694(16)$ & $29.78 \pm 2.562(25)$ & $20.93 \pm 1.178(42)$ & $27.44 \pm 1.899(29)$ & $\begin{array}{l}F_{(4,145)}=13.22 \\
p<0.0001\end{array}$ \\
\hline
\end{tabular}

"error shown is SEM with ( $n$ ) as the number of cells included in the analysis.

'Each parameter was analyzed using a one-way ANOVA to analyze the effect of age.

A

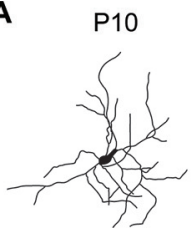

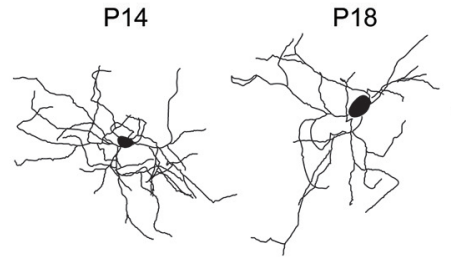

B
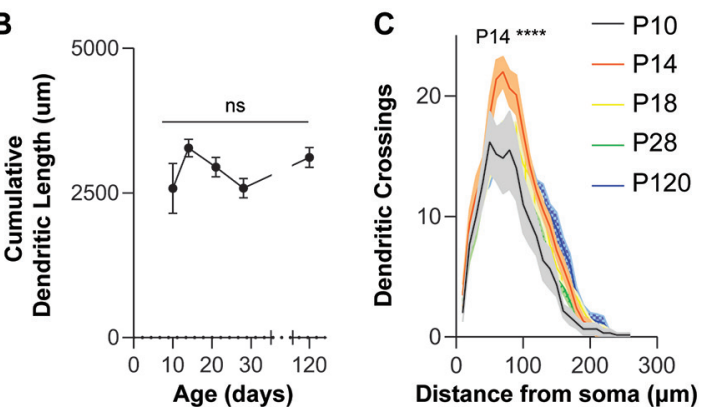

P28

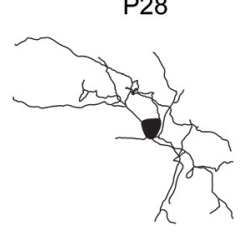

D

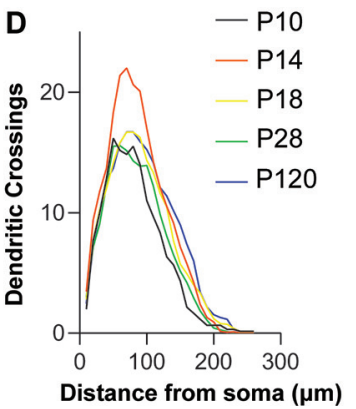

Figure 2. Postnatal maturation of $\mathrm{Chl}$ dendritic morphology. $\boldsymbol{A}$, Representative dendritic trees from Chls at specified ages. $\boldsymbol{B}$, There was no effect of age on the cumulative dendritic length of Chls. P10: $n=6(3$ mice), P14: $n=13(2)$, P18: $n=15(4)$, P28: $n=14(3)$, adult: $n=13(5)$. C, Sholl analysis reveals a significantly increased number of dendritic crossings in Chls from P14 mice 50-90 $\mu \mathrm{m}$ from the soma compared with all other ages. Data analyzed by two-way repeated measures ANOVA followed by post hoc Bonferroni test. Age $\times$ distance: $F_{(84,1232)}=1.430, p=0.008$. D, Mean dendritic crossings are shown without error bars for clarity. Data are the same as in $C * * * * p<0.0001$, ns is not significant, $p>0.05$.

At the time of recording, slices were transferred to the recording chamber and superfused with ACSF maintained at $34^{\circ} \mathrm{C}$. ChIs were identified based on the large soma size under IR/DIC optics using a $40 \times$ water immersion objective. Liquid junction potential was not corrected. Data were acquired using a Molecular Devices Axopatch 200, digitized using a Digidata $1440 \mathrm{~A}$ at $10 \mathrm{kHz}$, and filtered at $5 \mathrm{kHz}$.

Cell-attached and whole-cell recordings were accomplished using glass pipettes (2-6 M 2 ) filled with internal solution: $115 \mathrm{~mm}$ potassium gluconate, $20 \mathrm{~mm} \mathrm{KCl}, 20 \mathrm{~mm}$ HEPES, $1 \mathrm{~mm} \mathrm{MgCl}_{2}$, 2 mM MgATP, and $0.2 \mathrm{mM} \mathrm{Na}_{2} \mathrm{GTP}$ adjusted to $\mathrm{pH} 7.25$ with $\mathrm{KOH}$, osmolarity $285 \mathrm{mOsm}$ (Choi et al., 2020). Spontaneous firing frequency in cell-attached mode was recorded for $3 \mathrm{~min}$. Subsequently, a giga-ohm seal was achieved and the cell membrane was ruptured. Spontaneous action potential firing was recorded in current clamp, followed by measurement of the IV curve. Finally, inward currents were recorded in voltage clamp mode (See "Voltage Clamp Experiments" below).

Passive membrane properties were calculated as follows. Input resistance was calculated in current clamp from the change in voltage in response to a brief polarizing current injection $(-100 \mathrm{pA} ; 100 \mathrm{~ms})$. Tau was derived from an exponential decay fit in ClampFit of this current step. Capacitance was calculated by dividing tau by the input resistance. The medium afterhyperpolarization (mAHP) was calculated by subtracting the maximal hyperpolarization from the action potential threshold (Figure 3).

\section{Voltage clamp experiments}

Characterizations of SK, $\mathrm{I}_{\mathrm{A}}, \mathrm{I}_{\mathrm{h}}$, and INaP currents (Figures 4-7) were performed based on previously described methods in whole-cell voltage clamp experiments. For all experiments, baseline holding potential was $-60 \mathrm{mV}$.
To quantify SK, a tail current was elicited following a $10-\mathrm{ms}$ depolarizing voltage step $(+75 \mathrm{mV})$ from holding potential. Tail currents lasted $100-200 \mathrm{~ms}$ and were abolished by $25 \mathrm{~nm}$ apamin (Goldberg and Wilson, 2005). The peaks are reported as the elicited currents in ACSF minus the peak after $25 \mathrm{~nm}$ apamin was superfused onto the slice.

The $\mathrm{I}_{\mathrm{A}}$ quantification protocol was adapted from (Song et al., 1998). In the presence of TTX (500 nM), rapid-inactivating and slowlyinactivating currents were evoked by depolarizing steps $(+10$ to $+80 \mathrm{mV})$ from a hyperpolarized potential $(-100 \mathrm{mV})$. From a more depolarized potential $(-50 \mathrm{mV})$, only the slowly-inactivating component was elicited. Thus, the peak currents reported represent the rapidly-inactivating component as calculated by the subtraction of the two curves for the +80 - $\mathrm{mV}$ voltage step.

$\mathrm{I}_{\mathrm{h}}$ was quantified as reported in (Choi et al., 2020). Hyperpolarizing steps ( -10 to $-90 \mathrm{mV})$ from holding potential $(-60 \mathrm{mV})$ were held for $1 \mathrm{~s}$, and the current difference across the voltage step was quantified. The reported current is derived from the $-90-\mathrm{mV}$ voltage step.

$\mathrm{I}_{\mathrm{NaP}}$ was identified as the net-inward, ranolazine-sensitive component of the current evoked by depolarizing steps $(+10$ to $+40 \mathrm{mV}$ ) from the holding potential. Recordings of $\mathrm{I}_{\mathrm{NaP}}$ were performed in the presence of cadmium chloride $(400 \mu \mathrm{M})$ to block calcium channels (Maurice et al., 2004). Ranolazine, a selective inhibitor of persistent sodium channels, was bath applied at $50 \mu \mathrm{M}$ for 10-15 min after initial recording, and $\mathrm{I}_{\mathrm{NaP}}$ was reported as the difference in current at the end of the voltage step before and after drug application (Abrams et al., 2006; Tanimura et al., 2016; see Fig. 4).

\section{Dendritic reconstructions}

Dendritic reconstructions were obtained and analyzed essentially as described (Lieberman et al., 2018). Briefly, neurobiotin $(1 \mathrm{mg} / \mathrm{ml}$, Vector Laboratories) was added to the internal solution and allowed to diffuse into the cell for $15 \mathrm{~min}$ after the whole-cell configuration was established. The slice was then fixed in $4 \%$ paraformaldehyde in $0.1 \mathrm{M}$ phosphate buffer (PB), pH 7.4 overnight. Slices were stained with Alexa Fluor 488conjugated streptavidin (1:200, ThermoFisher) in $0.6 \%$ Triton X-100 in TBS. Finally, slices were mounted and coverslipped. Slides were imaged on a Leica SP5 confocal microscope in system optimized Z-stacks using a $20 \times$ objective. Dendritic trees were traced using the simple neurite tracer plugin in ImageJ. Traced neurites were collapsed into a maximum intensity projection and analyzed using the Sholl Analysis plugin.

\section{Cyclic voltammetry}

Electrochemical recordings of evoked DA release by FSCV were collected as detailed previously (Lieberman et al., 2018). Carbon fiber working electrodes were made by aspirating a single carbon fiber $(5 \mu \mathrm{m}$ in diameter) into a glass capillary (1.2-mm borosilicate, AM Systems), and pulling to a long taper with a micropipette puller (Sutter; P-97). Fibers 
were cut to an exposed length of $\sim 100 \mu \mathrm{m}$, and silver leads (0.015"; AM Systems) were permanently affixed inside the pipette by coating with colloidal silver paint before insertion. Striatal slices were prepared as for electrophysiology experiments (see "Electrophysiology" above). During recordings, slices were kept under constant superfusion of oxygenated ACSF $\left(2 \mathrm{ml} / \mathrm{min}, 34^{\circ} \mathrm{C}\right)$. A carbon fiber working electrode was placed in the dorsolateral striatum $\sim 50 \mu \mathrm{m}$ into the slice. A triangular voltage wave $(-450$ to $+800 \mathrm{mV}$ at $294 \mathrm{mV} / \mathrm{ms}$ vs $\mathrm{Ag} / \mathrm{AgCl})$ was applied across the working electrode every $100 \mathrm{~ms}$ and current was monitored with an Axopatch 200B amplifier (Molecular Devices) using a $5-\mathrm{kHz}$ low-pass Bessel Filter setting and $25-\mathrm{kHz}$ sampling rate. Signals were digitized using an ITC-18 board (Instrutech) and recorded with IGOR Pro 6.37 software (WaveMetrics), using in-house acquisition procedures (Mosharov, 2008). Slices were stimulated with a sharpened bipolar concentric electrode $(400 \mu \mathrm{m}$ max outer diameter; Pt/Ir; WPI), placed $\sim 150 \mu \mathrm{m}$ from the recording electrode, using an Iso-Flex stimulus isolator (AMPI) triggered by a Master- 9 pulse generator (AMPI). A single stimulus pulse $(100 \mu \mathrm{s} \times 200 \mu \mathrm{A})$ was applied every 2 min until stable release was achieved, after which three consecutive peaks were averaged to define singlepulse release magnitude. A train stimulus was then applied $(100 \mathrm{~Hz} \times$ five pulses). For $\mathrm{nAChR}$ antagonism, slices were then superfused with ACSF containing the competitive nAChR antagonist dihydro- $\beta$-erythroidine hydrobromide $(\mathrm{DH} \beta \mathrm{E} ; 1 \mu \mathrm{M})$. Slices were again stimulated with single pulses every 2 min until stable release (generally $10-15 \mathrm{~min}$ ) was achieved. Finally, slices were re-stimulated by the $100-\mathrm{Hz}$ train. In a given recording condition, train stimuli evoked no changes in subsequent single-pulse DA release (data not shown). Electrodes were calibrated by quantifying background-subtracted voltammograms in standard solutions of DA in ACSF prepared fresh each recording day. Concentration traces were made in IGOR Pro by collecting current over time at the peak DA oxidation potential normalized to the standard DA calibration factor.

\section{Two-photon imaging}

Two-photon images were acquired on a Prairie Ultima microscope system using PrairieView 4.3 software. Acute brain slices from DAT-ires-Cre $\mathrm{x}$ GCAMP3 mice were collected as described above, transferred into a chamber, and perfused with ACSF at room temperature. Samples were excited with a Coherent Chameleon Ultra two-photon laser tuned to $920 \mathrm{~nm}$, and images were collected through a photomultiplier tube channel with a 490 - to $560-\mathrm{nm}$ emission filter. The objective used was a $60 \times, 0.9 \mathrm{NA}$ water immersion lens (Olympus). Time series were acquired from a $100 \times 100$-pixel region of interest (ROI) located within the same field of view (1024 $\times 1024$ pixels $)$ as the electrode, at max speed $(\sim 0.15 \mathrm{~s} /$ frame $)$ for 480 frames, in Galvo mode with a dwell time OF $8 \mu$ s. Pulses $(200 \mu \mathrm{A} \times 100$ $\mu \mathrm{S})$ were delivered to the slice and triggered by a Master 8 pulse generator (AMPI) via a concentric bipolar electrode (WPI, see above). The slice received a single pulse or 10 pulses at $100 \mathrm{~Hz}$. This was repeated $\sim 8-12$ times per slice. Each ROI was quantified for mean pixel intensity in Image $(\mathrm{NIH})$ and the first and final $5 \mathrm{~s}$ were used to fit an exponential decay to each trace. The mean intensities were then normalized to the fit
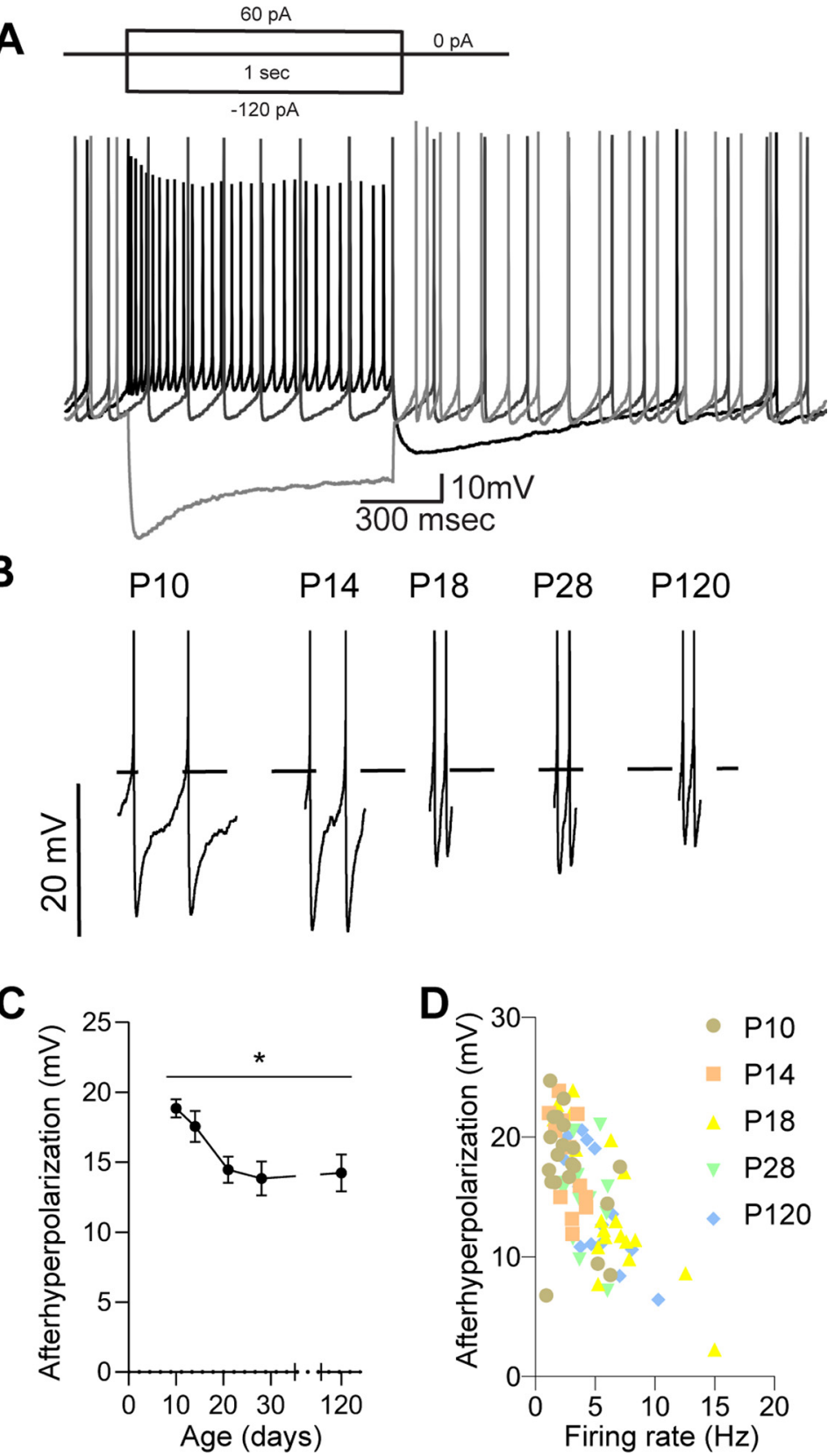

Figure 3. Chl AHP decreases between $\mathrm{P} 10$ and P120. $\boldsymbol{A}$, Sample current clamp trace of $\mathrm{Chl}$ activity in response to depolarizing and hyperpolarizing current injections. $\boldsymbol{B}$, Sample expanded traces of pairs of action potentials from Chls recorded at the specified ages. Dashed line denotes action potential threshold. $\boldsymbol{C}, A$ significant effect of age on the AHP ( $p=0.0102)$. For C, P10: $n=18$ cells (4 mice), P14: $n=16(2)$, P18: $n=23(4)$, P28: $n=15(3)$, adult: $n=28(6)$. $D$, Correlation between AHP and firing rate in Chls from all ages. $R^{2}=0.433 ; p<0.0001$ calculated for all data. $C$, is analyzed with a one-way ANOVA. $* p>0.05$.

to derive a baseline corrected trace to correct for photobleaching, and an average of traces was calculated for each slice, serving as each $N$.

\section{Experimental design and statistical analysis}

Electrophysiology data were analyzed offline using Clampfit software (Molecular Devices). Statistical analysis was conducted in GraphPad Prism 7. All bar graphs show the mean \pm SEM. Data comparing two variables were analyzed with a two-way ANOVA. Post hoc Bonferroni tests were conducted when significant differences were found with the two-way ANOVA. Data comparing one variable among more than two groups were analyzed with one-way ANOVA and Bonferroni post hoc tests and among two groups a two-tailed $t$ test. Data were not formally tested for parametric distribution. Group sizes were preliminarily determined based on previous studies (Lieberman et al., 2018). 


\section{Results}

The firing patterns and frequency of ChIs mature postnatally To address how the activity of ChIs matures postnatally, we performed cell attached recordings of visually identified ChIs at a range of ages across postnatal development. Cell-attached recordings were used to assess spontaneous activity to minimally disturb the intracellular milieu. ChIs were visually identified by their large cell bodies and cellular identity was further confirmed following conversion to the whole-cell configuration. In an initial dataset, we recorded from a total of 100 ChIs at P10, P14, P18, $\mathrm{P} 28$, and adults (P110-P120). Two cells recorded from a mouse at P10 were not spontaneously active in the cell-attached configuration but showed classic ChI characteristics in the whole-cell configuration and were included in subsequent analyses.

The frequency of spontaneous firing significantly increased over postnatal development (Fig. 1A,B). ChIs exhibit variation in the regularity of their firing and ChIs classically exhibit an inverse correlation between spontaneous firing frequency and the coefficient of variation of their firing in the acute brain slice (Bennett and Wilson, 1999). Consistently, the coefficient of variation of ChIs decreased during postnatal development (Fig. 1C). When the firing frequency and coefficient of variation was plotted for each individual recorded cell, a clear inverse correlation was observed between these parameters (Fig. 1D). Given these significant changes in firing frequency and regularity with age, we conclude that the spontaneous activity of ChIs matures postnatally.

Additional passive membrane properties for recorded ChIs are listed in Table 1.

\section{ChI dendritic arborization is mature by $\mathrm{P} 10$}

Neuronal firing patterns can be influenced by the complexity of their dendritic arbor (Mainen and Sejnowski, 1996). To analyze dendritic morphology, following cell-attached recordings, a whole-cell configuration was established and internal solution containing neurobiotin $(1 \mathrm{mg} / \mathrm{ml})$ was allowed to diffuse into the cell. Sections were postfixed, stained with fluorescently-labeled streptavidin and the filled cells were reconstructed using confocal microscopy. A subset of 61 cells were successfully reconstructed. Cumulative dendritic length was not significantly different between the ages examined (Fig. $2 A, B$ ). Interestingly, Sholl analysis revealed a significant transient increase in dendritic complexity in ChIs at P14 compared with P10, returning by P18 (Fig. $2 C, D)$. These data suggest that the dendritic arborization of ChIs is largely mature by P10 and reveal a previously unreported stage of dendritic overgrowth and regression at P14.

Changes in mAHP amplitude, but not interspike potential or action potential threshold, occur during the juvenile period As the dendritic arborization of ChIs did not change in parallel with spontaneous firing frequency, we examined additional properties of ChI physiology that could contribute to the increased activity observed during postnatal development.

First, we confirmed that the age-dependent increase in ChI spontaneous firing frequency also occurred in the whole-cell configuration (data not shown). The cells were found to exhibit classic features of ChIs including a sag in response to hyperpolarizing current injection and a slow AHP (sAHP) following depolarizing current injection (Fig. 3A; Kawaguchi, 1993; Bennett and Wilson, 1999). Cells without a sag or sAHP were excluded from the dataset.
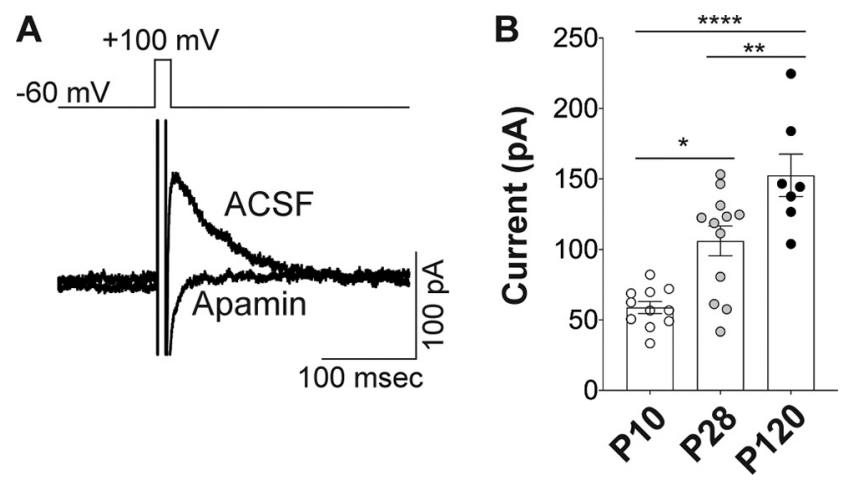

Figure 4. SK currents increase postnatally. $\boldsymbol{A}$, Sample voltage clamp recordings of the SK current in a Chl in ACSF and in ACSF with apamin. Note that apamin completely abolishes the current evoked by depolarizing the cell from -60 to $+40 \mathrm{mV}$. $\boldsymbol{B}$, The magnitude of the SK current increases postnatally. Data analyzed with one-way ANOVA. Age: $F_{(2,27)}=19.78$, $p<0.0001$; P10: $n=11$ cells (3 mice); P28: $n=12$ (3); P120: $n=7(3) ; * * * * p<0.0001$, $* * p<0.01, * p<0.05$.

We analyzed properties of $\mathrm{ChI}$ action potentials that could underlie changes in firing frequency. Sample pairs of spontaneous action potentials are shown in Figure $3 B$. One possible explanation for the increased spontaneous firing frequency of ChIs during postnatal development is that the action potential threshold becomes more hyperpolarized, allowing the threshold to be reached more readily. We found, however, that the average action potential threshold did not vary with age and, while spontaneous activity precludes measurement of a true "resting" membrane potential, the average interspike potential was unchanged with age as well (data not shown).

In contrast, the magnitude of the mAHP significantly decreased between P10 and adulthood (Fig. 3B,C). Further, a robust negative correlation was observed between $\mathrm{mAHP}$ and firing rate in ChIs (Fig. 3D), suggesting that a decrease in the mAHP may contribute to the developmental increase in spontaneous firing frequency. The mAHP reached the adult level by P18, indicating that additional changes in ChI physiology are responsible for increases in firing frequency that occur beyond this age.

\section{Maturation of outward currents responsible for the mAHP}

Given the correlation between mAHP and increasing firing rates in ChIs, we quantified the primary inward potassium currents thought to underlie the mAHP. The small conductance calciumactivated potassium current (SK) has been shown to be a primary contributor to the magnitude and kinetics of the mAHP (Bennett et al., 2000; Goldberg and Wilson, 2005). This transient apamin-sensitive current was evoked by a brief (10 ms) depolarizing pulse and its peak magnitude was quantified at P10, P28, and P120. We found that the SK current increased dramatically in the period from P10 to P28, and continued to increase into adulthood (Fig. 4A,B). Since the SK current positively correlates with the MAHP and negatively correlates with spontaneous firing frequency (Bennett et al., 2000; Goldberg and Wilson, 2005), changes in SK could not underlie the developmental decrease in $\mathrm{mAHP}$ and increase in firing frequency in ChIs.

ChIs also express calcium-independent voltage-gated potassium channels of the Kv1 and Kv4 subtypes that contribute to mAHP and firing rates of ChIs (Song et al., 1998; Tubert et al., 2016). Collectively termed the A-type potassium current $\left(I_{A}\right)$, we found that it also increased significantly across postnatal development, roughly doubling from P10 to P28 and again by P120 (Fig. $5 A, B) . \mathrm{I}_{\mathrm{A}}$ also contributes to the slope of the recovery to 

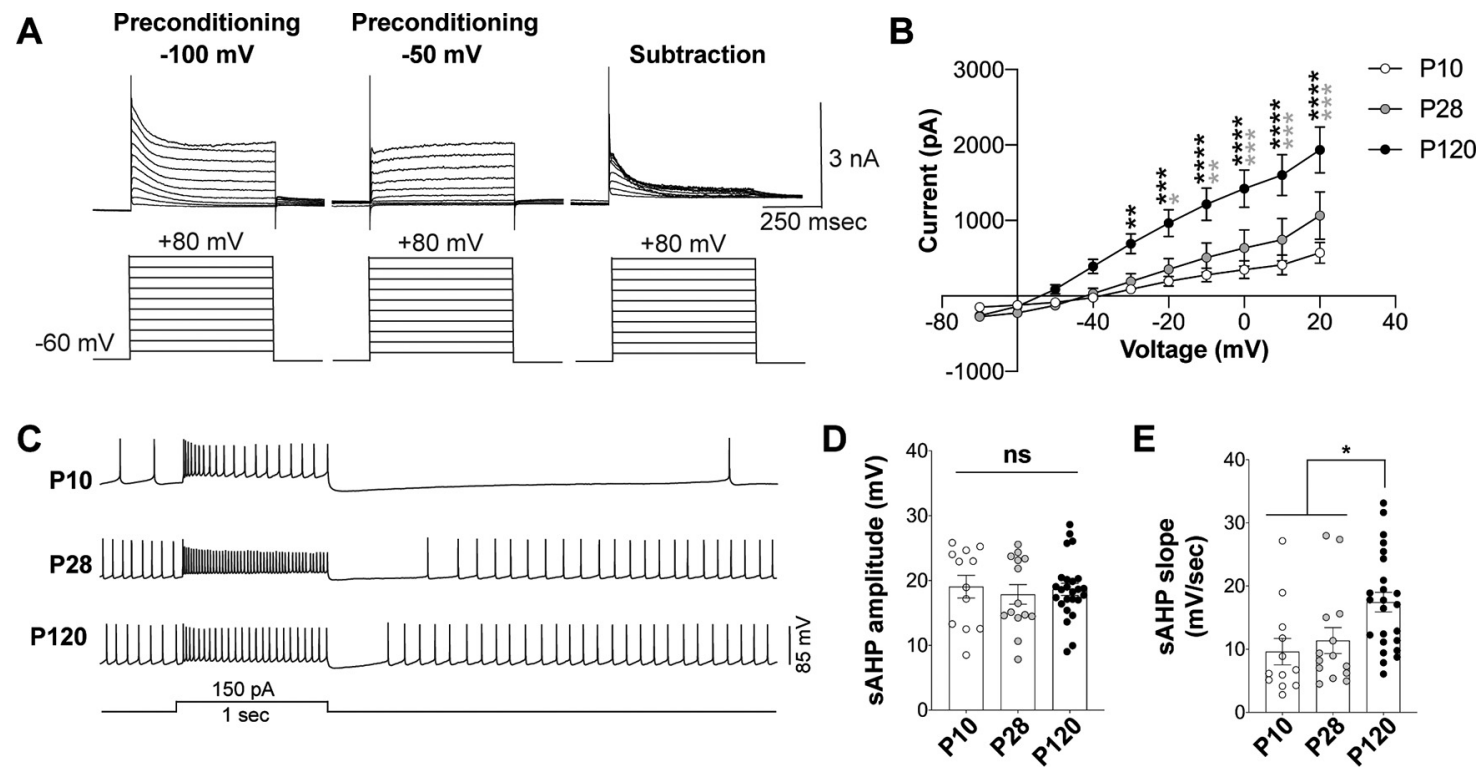

Figure 5. $I_{A}$ increases postnatally along with the recovery slope of the SAHP. A, Sample voltage clamp recordings of $I_{A}$ currents. Cells were preconditioned with a voltage step from $-60 \mathrm{mV}$ to either -100 or to $-50 \mathrm{mV}$. The cell was then stepped through a series of voltages. The difference current is $I_{A} \cdot \boldsymbol{B}$, Summary data revealing that $I_{A}$ increases from P10 to P120. Data analyzed with repeated measures two-way ANOVA with Bonferroni post hoc test. Age $\times$ voltage: $F_{(18,441)}=8.344$. P10: $n=21$ cells (3 mice); P28: $n=14(3)$; P120: $n=17(3)$. C, Sample current clamp recordings from Chls before, during and after a 150-pA current injection. The sAHP amplitude was measured as the change in voltage from minimum voltage after the current step to the AP threshold for the first AP fired. The SAHP recovery slope is that amplitude divided by the time to first spike. $\boldsymbol{D}$, There was no difference in sAHP amplitude between ages. Data were analyzed by one-way ANOVA. Age: $F_{(2,48)}=0.1755, p=0.8396$. $E$, The sAHP recovery slope is higher at P120 than at P28. Data were analyzed by one-way ANOVA. Age: $F_{(2,47)}=5.327, p=0.0082$; $* p<0.05, * * p<0.01, * * * p<0.001, * * * * p<0.0001$, ns is not significant, $p>0.05$.

action potential threshold after prolonged depolarizing stimuli, termed the sAHP slope (Connor and Stevens, 1971; Wilson and Goldberg, 2006). In support of our voltage clamp recordings which show an increased in $\mathrm{I}_{\mathrm{A}}$ across postnatal development, we found that this recovery slope increased during postnatal development in ChIs, independently from the amplitude of the sAHP (Fig. 5C-E). Thus, similar to SK, the developmental increases in $\mathrm{I}_{\mathrm{A}}$ would be expected to promote a more pronounced $\mathrm{mAHP}$ and slower firing rates, contrary to our measurements of these parameters over development.

We conclude that, while $\mathrm{SK}$ and $\mathrm{I}_{\mathrm{A}}$ increase significantly across postnatal development, these channels likely are not responsible for the identified developmental changes in firing properties of striatal ChIs.

\section{Maturation of inward currents}

A combination of $\mathrm{I}_{\mathrm{h}}$ and a persistent sodium current depolarize ChIs from the hyperpolarized mAHP. ( $\mathrm{I}_{\mathrm{NaP}}$; Bennett et al., 2000; Robinson and Siegelbaum, 2003). We first measured $I_{h}$ evoked by hyperpolarizing steps in voltage clamp, identifying significant increases in this current from P10 to adulthood (Fig. 6). However, $\mathrm{I}_{\mathrm{h}}$ deactivates around $-60 \mathrm{mV}$, a more hyperpolarized state than generally achieved by the spontaneously active neurons in our dataset. Thus, $\mathrm{I}_{\mathrm{NaP}}$ is acutely responsible for driving ChIs to their action potential threshold (Bennett et al., 2000). The $\mathrm{I}_{\mathrm{NaP}}$ conductance is responsible for a net inward current in response to depolarizing voltage steps from a $-60-\mathrm{mV}$ holding potential that "persists" for the duration of the step (Bennett et al., 2000). We quantified $\mathrm{I}_{\mathrm{NaP}}$ by subtraction of currents elicited by voltage steps between -65 and $-40 \mathrm{mV}$ after selectively blocking "late" sodium currents with ranolazine (Fig. 7A; Abrams et al., 2006; Tanimura et al., 2016). $\mathrm{I}_{\mathrm{NaP}}$ recordings were performed in the presence of cadmium chloride $(400 \mu \mathrm{M})$ to assist isolation of sodium currents by blocking calcium channels
(Wilson and Goldberg, 2006). Comparison before and after ranolazine revealed a net inward current elicited by depolarizing steps, with a magnitude that increased dramatically between P10 and P28, and continued to increase between P28 and adulthood (Fig. $7 B-E$ ). These data suggest that increased conductance through $\mathrm{I}_{\mathrm{NaP}}$ may contribute to the elevated spontaneous firing frequencies over postnatal development.

\section{Developmental increase in firing rate depends on $\mathrm{I}_{\mathrm{NaP}}$ and} not $I_{h}$

As we observed increases in both $\mathrm{I}_{\mathrm{NaP}}$ and $\mathrm{I}_{\mathrm{h}}$ conductances that were concomitant with developmentally increasing ChI firing rates, we tested the effects of $\mathrm{I}_{\mathrm{NaP}}$ and $\mathrm{I}_{\mathrm{h}}$ blockade on firing rates at $\mathrm{P} 10, \mathrm{P} 28$, and in adult mice. To exclude potential firing-rate rundown during longitudinal recordings before and after drug exposure, we compared firing rates at baseline with those of ChIs preincubated with ranolazine or the selective $\mathrm{HCN}$ blocker ZD7288 (ZD; BoSmith et al., 1993). Ranolazine decreased firing rates at $\mathrm{P} 28$ and $\mathrm{P} 120$ but not at P10, while $\mathrm{ZD}$ had no effect on spontaneous firing rate at any of the three ages (Fig. 8A,B). We further analyzed these traces and found that the mAHP was increased by ranolazine at P28 and P120 but not at P10, supporting an $\mathrm{I}_{\mathrm{NaP}}$-driven reduction in the $\mathrm{mAHP}$ as a biophysical mechanism for the increase in spontaneous ChI firing rates over postnatal development (Fig. 8C). We also confirmed that ZD treatment was sufficient to block $\mathrm{I}_{\mathrm{h}}$ in these cells. (Fig. $8 D, E$ ). These data suggest that the $\mathrm{I}_{\mathrm{NaP}}$ conductance mediates the developmental increase in firing rates between P10 and adulthood, while the firing rate of early postnatal (P10) ChIs is $\mathrm{I}_{\mathrm{NaP}}$ independent (Fig. 8A,B).

\section{Summation of DA release in response to high frequency stimuli}

ACh released from striatal ChIs modulates local DA release via activation of nAChRs on DA axon terminals (Cachope et al., 
A

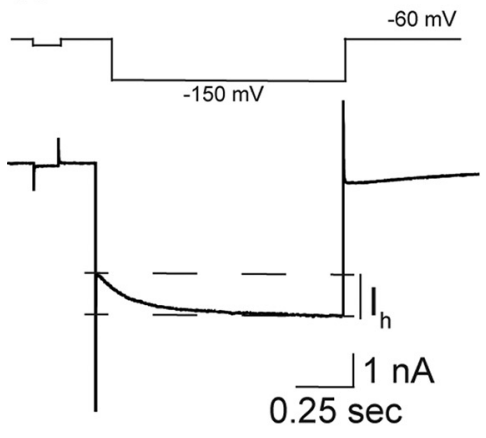

B

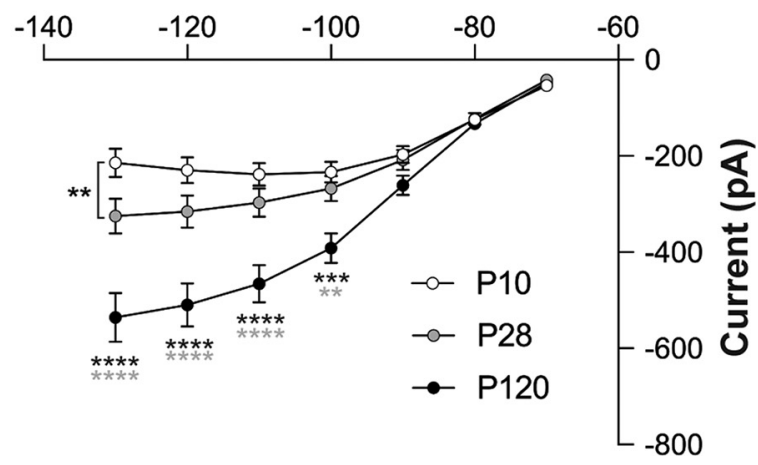

Figure 6. $I_{h}$ increases postnatally. $A$, Sample voltage clamp recordings of the $I_{h}$ current in a Chl. $B$, $I_{h}$ increases from P28 to P120. Data analyzed with repeated measures two-way ANOVA with Bonferroni post hoc test. Age $\times$ voltage: $F_{(12,570)}=18.80, p<0.0001$. P10: $n=31$ cells (6 mice); P28: $n=39$ (7); P120: $n=28(6) ; * * * * p<0.0001, * * * p<0.001, * * p<0.01$.

A

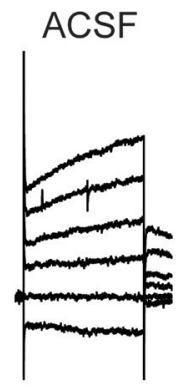

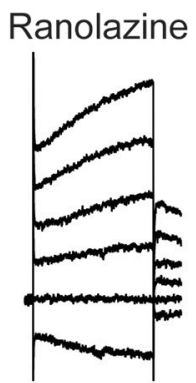

Subtraction
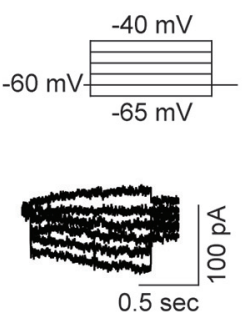

B

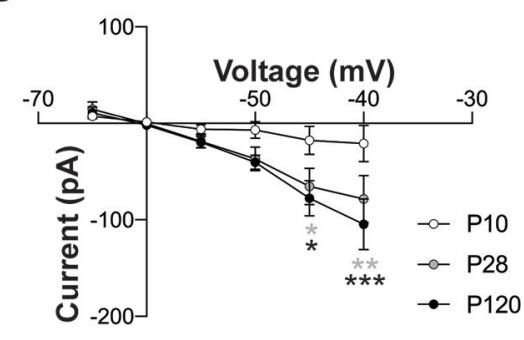

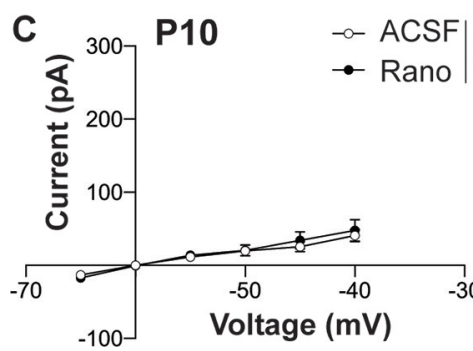
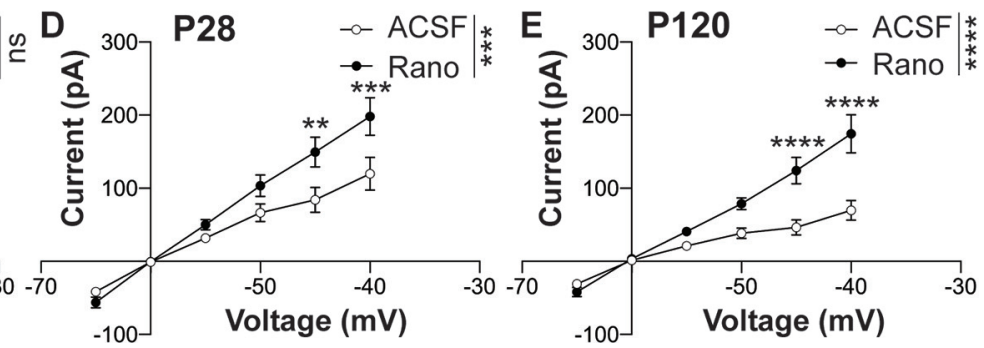

Figure 7. The persistent sodium current $\left(\mathrm{I}_{\text {NaP }}\right)$ increases during postnatal development in $C \mathrm{hls}$. $\boldsymbol{A}$, Sample voltage clamp recording demonstrating $\mathrm{I}_{\text {Nap. }}$. Voltage clamp recordings were conducted in $\mathrm{CdCl}_{2}$ to eliminate calcium currents (Bennett et al., 2000). Treatment with ranolazine $(1 \mu \mathrm{m})$ reveals the $\mathrm{I}_{\mathrm{NaP}}$ current. $\boldsymbol{B}$, Aggregate subtracted currents show a significant increase in $\mathrm{I}_{\mathrm{NaP}}$ between P10 and P28 or adult (P120) Chls. P10: $n=17$ cells (3 mice), P28: $n=15(7)$, adult: $n=10(6)$. Data analyzed by two-way repeated measure ANOVA followed by Bonferroni post hoc test. Age $\times$ voltage: $F_{(10,195)}$ $=2.529, p=0.0069$. C $-\boldsymbol{E}$, IV curves in ACSF or in the presence of ranolazine at (C) P10, (D) P28, or (E) adult (P120). Data analyzed by two-way repeated measure ANOVA followed by Bonferroni post hoc test. P10: age $\times$ voltage: $F_{(5,135)}=0.3352, p=0.8909$; P28: age $\times$ voltage: $F_{(5,160)}=4.998, p=0.0003$; adult: age $\times$ voltage: $F_{(5,9)}=11.33, p<0.0001$. *p $<0.05$, **p $<0.01, * * * p<$ $0.001, * * * * p<0.0001$, ns is not significant, $p>0.05$.

2012; Threlfell et al., 2012). The interaction between DA and $\mathrm{ACh}$ can be probed in the acute brain slice, where it has been shown that $\mathrm{nAChR}$ activation on DA axons acts as a frequencydependent filter on DA release (Zhou et al., 2001; Rice and Cragg, 2004; Zhang and Sulzer, 2004). In the adult, ACh amplifies DA release in response to isolated or low-frequency stimuli, whereas prolonged stimulation or robust exogenous nAChR activation (for example, by nicotine) causes $\mathrm{nAChR}$ desensitization and thus decreases evoked DA release. We recently reported that the juvenile striatum shows relatively low levels of DA release in response to single electrical pulses (Sturman et al., 2010; Sturman and Moghaddam, 2012; Lieberman et al., 2018). The changes in ChI activity over development led us to hypothesize that the low levels of ChI firing and excitability in the juvenile striatum $(\sim \mathrm{P} 10)$ may correspond with low levels of ACh signaling that underlie these developmental differences in DA release properties.
To address this possibility, DA release was measured using FSCV in acute brain slices from mice at P10, P28, and P120, following intrastriatal electrical stimulation. Consistent with our recent report (Lieberman et al., 2018), DA release following a single pulse increased significantly with age (Fig. 9A,B). We found, however, that a high frequency stimulus train significantly increased evoked DA release beyond a single stimulus at P10, while this increased response to multiple high frequency stimuli did not persist at P28 or P120 (Fig. 9B,C). Previous studies showed frequency-dependent effects of nicotinic drugs on summation of DA release across high-frequency stimuli in the nAChR-inhibited state in adult acute striatal slices (Rice and Cragg, 2004; Zhang and Sulzer, 2004). For the purposes of this study, we chose the stimulation frequency $(100 \mathrm{~Hz})$ shown in these original studies to elicit the most efficient summation of DA release. We report these data as the ratio of evoked DA following $100-\mathrm{Hz}$ stimuli to a single pulse $(100 \mathrm{~Hz} / 1 \mathrm{p}$; Fig. $9 \mathrm{C})$ : the 

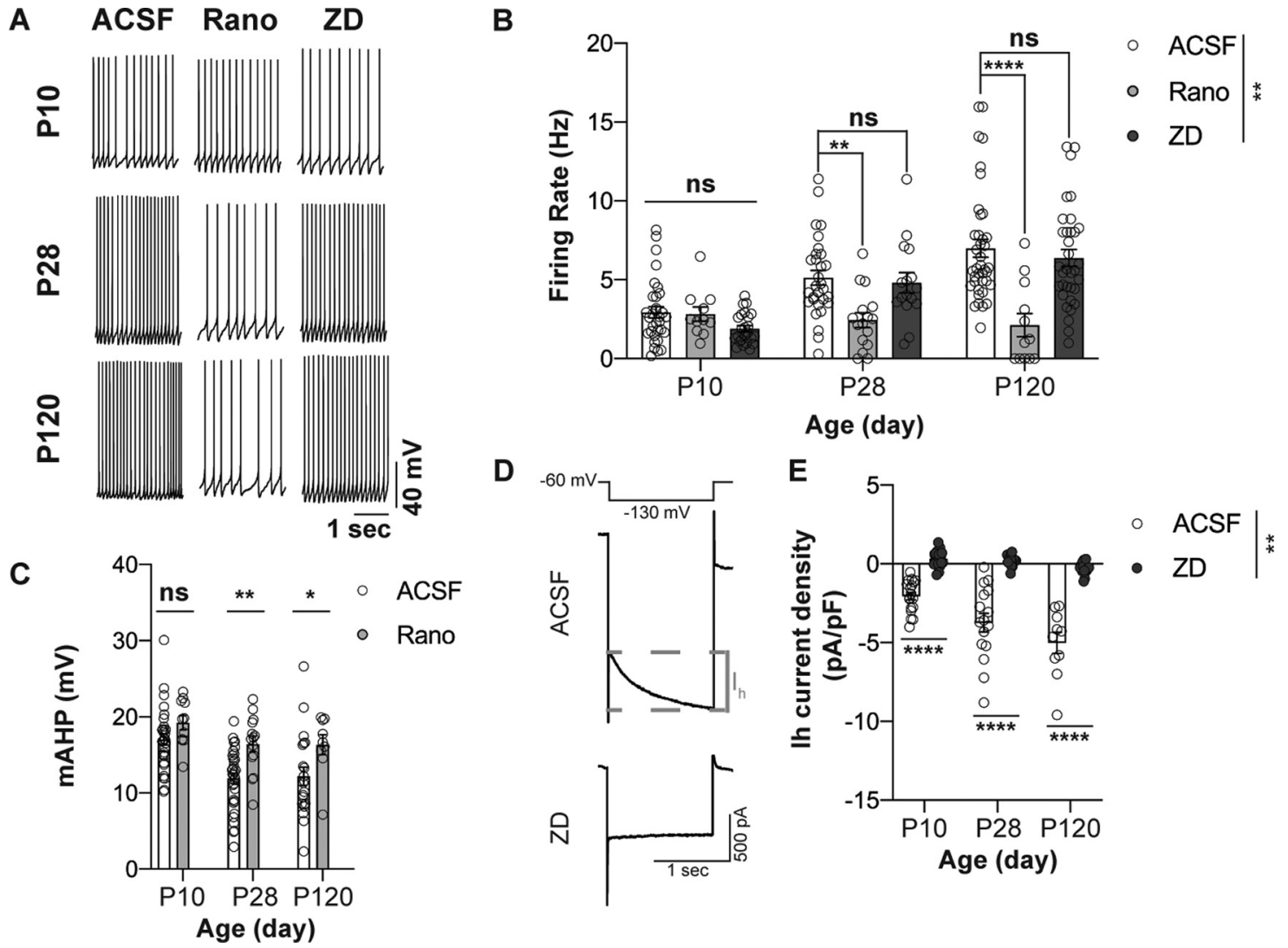

Figure 8. The $I_{\text {NaP }}$ current, but not $I_{h}$, underlies age-dependent increases in Chl firing frequency. $\boldsymbol{A}$, Sample current clamp recordings of spontaneous action potentials from Chls at specified ages incubated with vehicle (ACSF), $1 \mu \mathrm{m}$ ranolazine (Rano), or $1 \mu \mathrm{m} \mathrm{ZD7200} \mathrm{(ZD).} \mathrm{B,} \mathrm{Rano} \mathrm{reduces} \mathrm{Chl} \mathrm{firing} \mathrm{rate} \mathrm{at} \mathrm{P28} \mathrm{and} \mathrm{P120} \mathrm{(adult)} \mathrm{but} \mathrm{not} \mathrm{at} \mathrm{P10,} \mathrm{while} \mathrm{ZD} \mathrm{does} \mathrm{not} \mathrm{affect} \mathrm{Chl} \mathrm{firing} \mathrm{rate} \mathrm{at} \mathrm{any} \mathrm{age.} \mathrm{Data}$ analyzed by two-way ANOVA with Bonferroni post hoc test. Age $\times$ drug: $F_{(4,205)}=4.539, p=0.0016$. ACSF: P10: $n=32$ cells (5 mice), P28: $n=30(5)$, adult: $n=39(6)$. Rano: P10: $n=11$ cells (3 mice), P28: $n=16(3)$, adult: $n=12(4)$. ZD: P10: $n=24$ cells (3 mice), P28: $n=16(3)$, adult: $n=34(4)$. C, Treatment with Rano leads to increased mAHP at P28 and P120 but not at P10. Data analyzed by two-way ANOVA with Bonferroni post hoc test. ACSF: P10: $n=32$ cells (5 mice), P28: $n=30(5)$, adult: $n=39$ (6). Rano: P10: $n=11$ cells (3 mice), P28: $n=16(3)$, adult: $n=12$ (4). Age $\times$ drug: $F_{(2,112)}=0.7185, p=0.4897$. Age: $F_{(2,112)}=9.184, p=0.0002$. Drug: $F_{(1,112)}=17.09, p<0.0001$. D, Sample voltage clamp recordings of $I_{h}$ from Chls recorded in control ACSF or ACSF with $1 \mu \mathrm{m} Z$ ZD. $E$, ZD eliminates $I_{h}$ in Chls at P10, P28, and in adulthood. Data analyzed by two-way ANOVA with Bonferroni post hoc test. Age $\times$ drug: $F_{(2,90)}=7.048, p=0.0014$. ACSF: P10: $n=18$ cells (5 mice), P28: $n=16(5)$, adult: $n=10(6)$. ZD: P10: $n=22$ cells (3 mice), P28: $n=15(3)$, adult: $n=15(4) . * p<0.05, * * p<0.01, * * * * p<0.0001$, ns is not significant, $p>0.05$.

ratio is significantly lower at P28 and P120 than at P10. We thus conclude that DA release properties mature between P10 and P28.

The dynamics of neurotransmitter release are heavily dependent on calcium influx and buffering. To address whether calcium entry differed in DA axons between P10 and adulthood, we generated transgenic mice expressing a calcium indicator, GCaMP3, in DA axons by crossing the DAT-Ires-Cre driver line (Bäckman et al., 2006) with the Ai38 line harboring a floxed allele of GCaMP3 in the Rosa26 locus (Zariwala et al., 2012; Lieberman et al., 2017). We confirmed specific GCaMP3 expression in DA neurons and axons at P10 and in adults (data not shown; Lieberman et al., 2017). To test whether calcium dynamics were distinct at P10 compared with adulthood, we generated acute brain slices and imaged GCaMP3 fluorescence using twophoton microscopy. A single-pulse electrical stimulus in the striatum yielded a smaller change in fluorescence in striatal DA axons at P10 than at P120 (Fig. 9D,E). Remarkably, however, stimulation with electrical pulses at $100 \mathrm{~Hz}$ yielded an equivalent change in fluorescence at P10 and in adults (Fig. $9 D, E)$. There was a significant interaction between age and stimulation, with DA axons at P10 displaying significantly increased summation of fluorescence evoked by high frequency stimuli compared with adults (Fig. $9 F, G$ ). These data suggest that the postnatal maturation of DA release dynamics may arise from changes in calcium dynamics.
We then considered that the similar levels of DA evoked by $100-\mathrm{Hz}$ stimulation at P10 and P28 (Fig. 9B) suggests that the lower DA at P10 evoked by a single pulse may not arise from low stores of axonal DA but rather from differences in the regulation of DA release properties in the immature striatal microcircuit. In the adult, the relative absence of DA release summation arises from $n A C h R$ activation on DA axons (Sulzer et al., 2016). Given the efficiency of DA release summation evoked by high-frequency stimuli in the juvenile striatum, we hypothesized that signaling through the $\mathrm{nAChR}$ would be occluded in the juvenile. We thus tested the effect of a $\mathrm{nAChR}$ antagonist, $\mathrm{DH} \beta \mathrm{E}$, on single-stimulus release magnitude and release summation evoked by a $100-\mathrm{Hz}$ stimulus. Evoked DA release was first measured in response to a single pulse and a train of five pulses $(100 \mathrm{~Hz})$, after which $\mathrm{DH} \beta \mathrm{E}$ was superfused onto the slice and evoked DA was measured in response to the same stimulus pattern. $\mathrm{DH} \beta \mathrm{E}$ significantly increased the $100 \mathrm{~Hz} / 1 \mathrm{p}$ ratio at P28 and in the adult but had no effect at P10 (Fig. 10A,B). These data suggest that the difference in DA release properties between P10, P28, and P120 arises from an increase in cholinergic signaling in the striatum during early postnatal maturation.

\section{Discussion}

We have investigated the ontogeny of ChI firing and ACh-DA interactions during postnatal development of the striatum. Using 


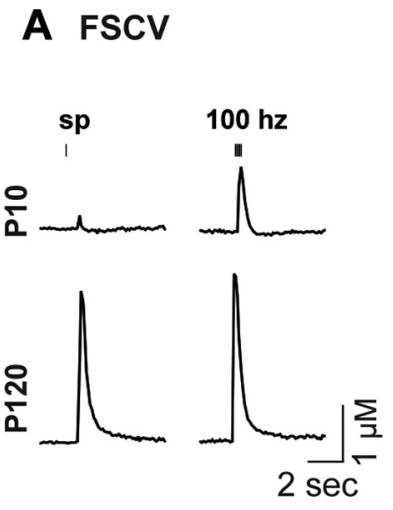

B FSCV

C FSCV

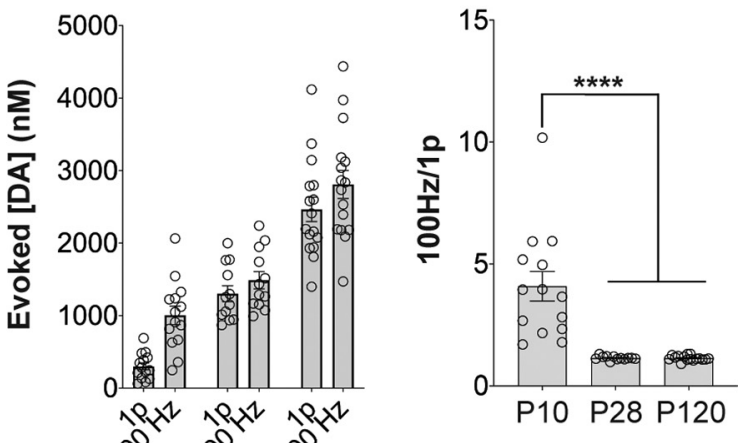

D DA axon $\mathrm{Ca}^{++}$imaging

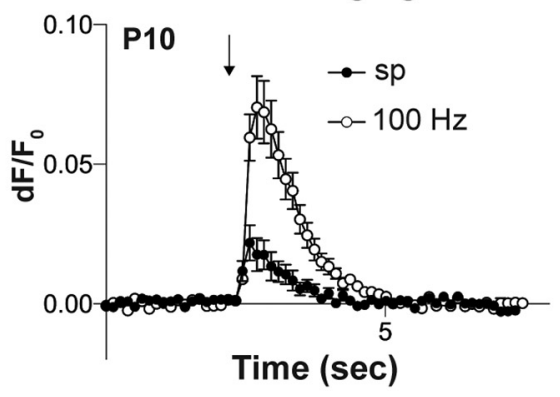

F DA axon $\mathrm{Ca}^{++}$imaging

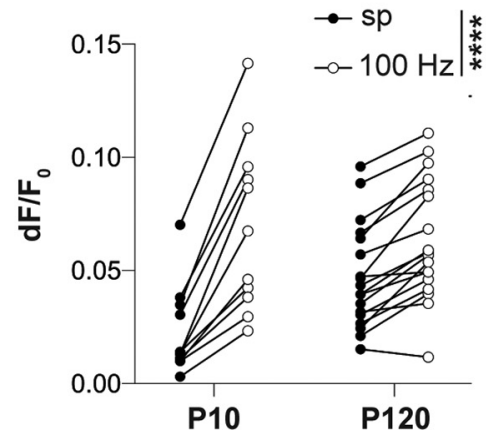

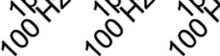
$\overline{\mathrm{P} 10} \overline{\mathrm{P} 28} \overline{\mathrm{P} 120}$

E DA axon $\mathrm{Ca}^{++}$imaging

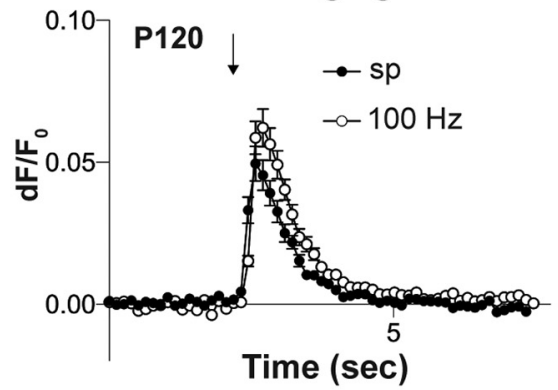

G DA axon $\mathrm{Ca}^{++}$imaging

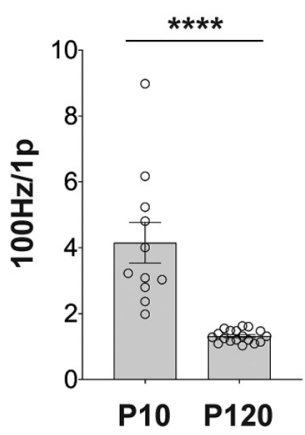

Figure 9. The summation of DA release decreases in fidelity during postnatal development. $A$, Sample cyclic voltammetry recordings of evoked striatal DA release with a single pulse (sp) or five pulses at $100 \mathrm{~Hz}$ at P10 or P120 striatal slices. Scale bar: $200 \mathrm{~nm}$ and $200 \mathrm{~ms}$. $\boldsymbol{B}$, Absolute peak concentrations of evoked DA release following a single pulse (1p) or five pulses at $100 \mathrm{~Hz}$. C, Absolute concentrations from $\boldsymbol{B}$ displayed as the ratio of DA evoked with five pulses at $100 \mathrm{~Hz}$ to a single pulse in striatal slices from mice aged P10, P28, or adult. P10: $n=14$ slices from 4 mice; P28: $n=12$ slices from 3 mice; adult: $n=14$ slices from 3 mice. Data analyzed by one-way ANOVA followed by Bonferroni post hoc test. $D, E, \Delta F / F$ of GCaMP3 in DA axons within acute slices from $(\boldsymbol{D})$ P10 or $(\boldsymbol{E})$ adult mice. Arrow indicates time of electrical stimulation with either a single pulse or pulses at $100 \mathrm{~Hz}$. $F, \Delta \mathrm{F} / \mathrm{F}$ from each slice after a single pulse or $100-\mathrm{Hz}$ stimulation. Two-way repeated measures ANOVA: age $\times$ frequency, $F_{(1,27)}=40.04, p<0.0001$. $G$, Fold change in $\Delta F / F$ after $100-\mathrm{Hz}$ stimulation compared with a single pulse. $T_{(27)}=5.902, p<0.0001$. P10: $n=11$ slices from 3 mice; adult: $n=18$ slices from 6 mice. $* * * * p<0.0001$.

patch-clamp electrophysiology and FSCV, we identified changes in ChI intrinsic physiology and cholinergic modulation of DA release during early postnatal development and into adulthood. Notably, the most prominent changes in ChI physiology occur between P10 and P28, a developmental period when significantly more complex motor patterns become expressed (Altman and Sudarshan, 1975; Doremus-Fitzwater et al., 2012). Our results complement previous reports of neurochemical maturation of cholinergic signaling during this window (Coyle and Campochiaro, 1976; Coyle and Yamamura, 1976; Sawa and Stavinoha, 1987) and suggest links between $\mathrm{ChI}$ physiology in the juvenile striatum and the maturation of an animal's behavioral repertoire.
The maturation of the striatal cholinergic system

The striatum contains the highest concentration of ACh in the brain (Fibiger, 1982). In contrast to other brain regions, however, the majority of striatal cholinergic innervation arises from a population of interneurons rather than from afferent innervation by projection neurons, although additional cholinergic projections to the striatum originate in the brainstem (Kimura et al., 1980; Henderson, 1981; Dautan et al., 2014).

ChIs are generated between embryonic day (E)13 and E15 (Phelps et al., 1989), before the appearance of striatal projection neurons or non-cholinergic striatal interneurons (E15-P2; van der Kooy and Fishell, 1987; Song and Harlan, 1994; Liao et al., 2008). Although a major biosynthetic enzyme for $\mathrm{ACh}$, choline acetyltransferase (ChAT), is present in ChIs at birth, ChAT expression levels increase linearly during the first four postnatal weeks and reach adult levels around P28 in both rat and mouse (Guyenet et al., 1975; Coyle and Yamamura, 1976; Phelps et al., 1989; Aznavour et al., 2003). Striatal ACh levels follow a similar developmental trajectory (Coyle and Campochiaro, 1976; Coyle and Yamamura, 1976; Phelps et al., 1989). The protracted postnatal maturation of ACh neurochemistry has been suggested to underlie a delayed interaction between cholinergic and dopaminergic pharmacology in the developing rodent, which reaches functional maturity around P20 (Burt et al., 1982; Fitzgerald and Hannigan, 1989). In addition, although striatal ChIs appear in tandem with basal forebrain cholinergic neurons, their functional development lags behind the basal forebrain system (Phelps et al., 1989), suggesting that cues specific to the striatum may contribute to ChI maturation.

Here, we extend the analysis of the ontogeny of the striatal cholinergic system by electrophysiological analysis of ChIs during mouse postnatal development. We find that the maturation of $\mathrm{ChI}$ firing frequencies mirrors the time course of tissue ACh levels and expression of ChAT, suggesting that ACh itself may provide a feedback mechanism that regulates the maturation of ChI physiology during postnatal development. We also find that the time course of the maturation of ChI activity is similar to that of DA release, suggesting a potential reciprocal interaction between DA signaling and ChI maturation.

\section{Biophysical mechanisms controlling the maturation of $\mathrm{ChI}$ firing}

The frequency of tonic ChI firing is determined by the coordinated activity of intrinsic conductances (Wilson et al., 1990; Bennett et al., 2000; Goldberg and Wilson, 2005; Goldberg and Reynolds, 2011). 
A

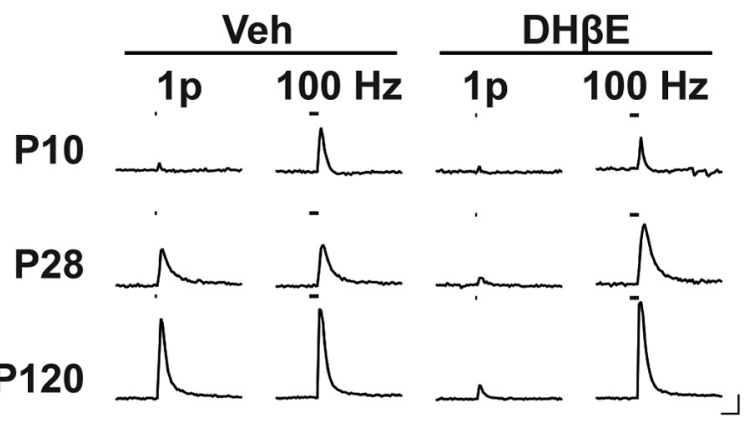

B

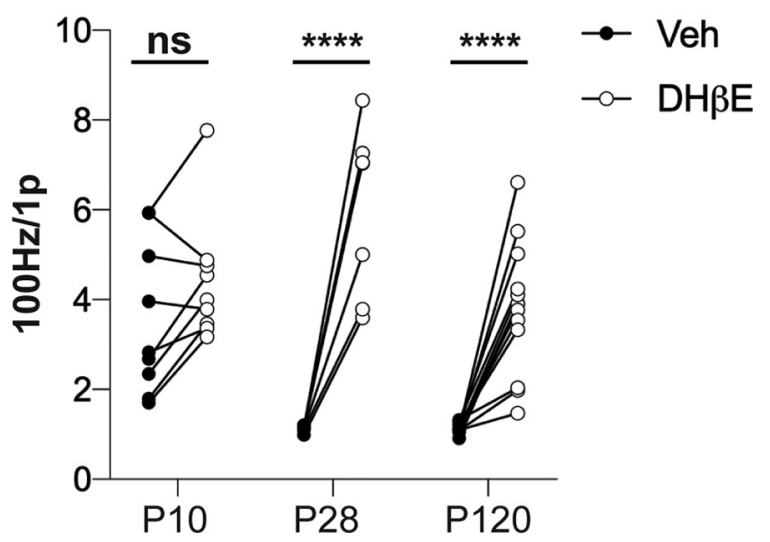

Figure 10. The effect of $n A C h R$ blockade on DA release is occluded at P10. A, Sample cyclic voltammetry recordings of evoked striatal DA release with a single pulse (sp) or five pulses at $100 \mathrm{~Hz}$ at $\mathrm{P} 10, \mathrm{P} 28$, or in adult striatal slices in the presence of absence of $\mathrm{DH} \beta \mathrm{E}$ $(1 \mu \mathrm{m})$. Scale bar: $1 \mu \mathrm{m}$ and $1 \mathrm{~s} . \mathbf{B}, \mathrm{DH} \beta \mathrm{E}(1 \mu \mathrm{m})$ significantly increases the $100 \mathrm{~Hz} / 1 \mathrm{p}$ ratio at P28 and P120 but not at P10. Data analyzed with two-way repeated measures ANOVA followed by Bonferroni post hoc test. Age $\times$ drug: $F_{(2,26)}=15.26, p<0.0001 ; P 10: n=9$ slices from 4 mice; P28: $n=7$ slices from 2 mice; adult: $n=13$ slices from 3 mice. $* * * * p<$ 0.0001 , ns is not significant, $p>0.05$.

What drives the maturation of $\mathrm{ChI}$ spontaneous firing identified here?

The amplitude of the mAHP decreases from P10 to p120 (Fig. $3)$. In the adult, the kinetics of cell repolarization leading to the mAHP are driven by the activities of SK, BK, and A-type potassium currents ( $\mathrm{I}_{\mathrm{a}}$; Song et al., 1998; Goldberg and Wilson, 2005). Contrary to the primary observations of decreased mAHP amplitudes and increased firing rates, however, our measurements of SK and $\mathrm{I}_{\mathrm{a}}$ reveal significantly increased current densities over the postnatal period (Figs. 4, 5). While we did not specifically isolate BK currents, we observed a marginal but significant decrease in action potential widths across development (data not shown), consistent with increased BK current as well (Goldberg and Wilson, 2005). SK and BK currents are mediated not only by channel levels and function but also in response to changes in calcium entry during action potential firing, a process that initiates SK and BK channel opening (Bennett et al., 2000). Future efforts should determine the mechanisms by which the activities of these channels are altered during postnatal development.

Given the overall decrease in mAHP amplitude over development, as well as further firing rate increases beyond the age at which the mAHP reaches mature levels (P18), an additional mechanism must drive the increase in spontaneous ChI firing and the reduction of $\mathrm{mAHP}$ independent of SK and $\mathrm{I}_{\mathrm{a}}$ conductances. We found that the magnitudes of both of the inward currents, $I_{h}$ and $I_{N a P}$, increase between P10 and adulthood, which may eclipse the influence of increased outward currents on $\mathrm{mAHP}$ and drive faster firing rates. We found that blockade of $I_{h}$ with ZD had no significant effect on firing rates at any age, which is consistent with our data indicating that these neurons were typically more depolarized than the voltage range in which $I_{h}$ is active.

$\mathrm{I}_{\mathrm{NaP}}$ blockade, in contrast, effectively decreased the firing rates of adult cells to the levels observed in P10 cells, while $\mathrm{I}_{\mathrm{NaP}}$ blockade at P10 had no effect. These results indicate that the developmental increase in firing rate is driven by increased $\mathrm{I}_{\mathrm{NaP}}$. Because $\mathrm{I}_{\mathrm{NaP}}$ is active across the entire subthreshold voltage range of the ChI, we tested whether this current mediates the decrease in mAHP during the early (P10-P18) postnatal period in a manner independent from developmental changes in SK, BK, or A-type currents. We found that ranolazine increased the mAHP amplitudes at P28 and P120, but had no effect at P10, suggesting that an $\mathrm{I}_{\mathrm{NaP}}$-driven decrease in $\mathrm{mAHP}$ drives the developmental ChI firing rate increase.

Previous studies in rat cortex and hippocampus have demonstrated that the $\mathrm{I}_{\mathrm{NaP}}$ conductance is developmentally regulated in pyramidal neurons, playing a dynamic role in the excitability of these populations as the animals age (Alzheimer et al., 1993; Lunko et al., 2014). As further research seeks to identify the upstream developmental determinants of increasing $\mathrm{I}_{\mathrm{NaP}}$ activity, it will be important to consider whether these developmental signals act system-wide on neuronal populations for which activity is driven by $\mathrm{I}_{\mathrm{NaP}}$, or whether these developmental trajectories occur independently.

\section{Maturation of DA release properties depends on cholinergic signaling}

We hypothesized that the maturational dynamics we observed in striatal ChIs may correspond with the functional maturation of striatal cholinergic signaling, and in turn dynamically regulate DA release in the striatum. DA release properties, which are regulated by nAChR activity in adulthood (Zhou et al., 2001; Rice and Cragg, 2004; Zhang and Sulzer, 2004; Cachope et al., 2012; Threlfell et al., 2012; Sulzer et al., 2016), were measured using FSCV. We previously reported that evoked DA release increases during postnatal development in the striatum (Lieberman et al., 2018). In the adult striatum, electrical stimuli elicit DA release through two mechanisms: cell-autonomous depolarization of DA axons, and via activation of nAChRs on DA axons by ACh (Zhou et al., 2001; Rice and Cragg, 2004; Zhang and Sulzer, 2004; Sulzer et al., 2016). Notably, nAChR antagonists effectively block most of the DA release evoked by a single electrical stimulus in the adult striatum. Reduced cholinergic signaling in the striatum could thus contribute to decreased DA evoked by a single stimulus during the early juvenile period.

While acute activation of the nAChR facilitates evoked release, prolonged stimulation or pharmacological intervention cause desensitization of the $\mathrm{nAChR}$ and a consequent reduction in DA release capacity. Thus, while DA release in the adult acute striatal slice preparation is largely independent of stimulus frequency or number of grouped stimuli, nAChR antagonism or desensitization elicits a capacity for summation of DA release with multiple stimuli at high frequency (Zhou et al., 2001; Rice and Cragg, 2004; Zhang and Sulzer, 2004; Sulzer et al., 2016). Here, we find that in contrast to these previous reports from adult mice, DA release is efficiently summed across multiple high frequency stimuli at P10, even without pharmacological intervention. We confirmed that, in addition to DA release itself, electrically-evoked increases in calcium within DA axons also 
undergo postnatal maturation, as adult DA axons exhibit higher fluorescence evoked by a single pulse, while DA axons at P10 exhibited significantly more summation of fluorescence evoked by high frequency stimuli compared with the adult. Moreover, a $\mathrm{nAChR}$ antagonist did not enhance the summation of DA release at P10, but did so at P28 and in adults. We conclude that altered DA release properties in the juvenile striatum, including decreased release in response to a single stimulus and increased summation of DA release across grouped stimuli, are mediated by an absence of signaling through the nAChR, and that this process matures during the early postnatal period.

We note that we did not directly correlate changes in ChI firing patterns with $\mathrm{ACh}$ release. It is notable that tissue $\mathrm{ACh}$, ChAT, and acetylcholinesterase (AChE) each increase during postnatal development (Guyenet et al., 1975; Butcher and Hodge, 1976; Coyle and Yamamura, 1976; Murrin and Ferrer, 1984) with a time course that mirrors the maturation of spontaneous ChI firing we report. Recently developed fluorescent sensors can measure changes in extracellular ACh levels (Jing et al., 2018) and may contribute to further analysis of these relationships. A non-exclusive additional mechanism related to the regulation of DA release by $\mathrm{ACh}$ could be related to maturational changes in the amount, type, or coupling of nAChR subunits, or cell types expressing striatal nAChRs.

In conclusion, the electrophysiological maturation of striatal neurons during the postnatal period is associated with changes in intrinsic excitability and excitatory and inhibitory synaptogenesis (Cazorla et al., 2012; Kozorovitskiy et al., 2012, 2015; Lieberman et al., 2018; Kuo and Liu, 2019). Recent work aimed at defining the mechanisms that control striatal maturation have focused on the SPN and have highlighted a role for circuit mechanisms (Kozorovitskiy et al., 2012), neuromodulation (Kozorovitskiy et al., 2015; Lieberman et al., 2018), and cell-autonomous pathways that contribute to postnatal development of these cells (Oldenburg and Ding, 2011; Peixoto et al., 2016, 2019; Guevara et al., 2020; Lieberman et al., 2020; Khandelwal et al., 2021). Here, we extend this analysis by focusing on striatal ChIs, neurons that are thought to play central roles in striatal action and sensorimotor learning. We find that key features of intrinsic ChI electrophysiology mature during the first four postnatal weeks, a period of acquisition of complex motor skills and enhanced sensitivity to reward. We identify a significant increase in $\mathrm{I}_{\mathrm{NaP}}$ that underlies increased spontaneous firing frequencies over this developmental window and into adulthood. Importantly, these maturational steps occur in tandem with changes in DA release properties that are mediated by cholinergic signaling, indicating that $\mathrm{ChI}$ and DA neurons may play reciprocal roles in the developmental regulation of striatal function. In combination with our understanding of SPN maturation, these data provide further insight into potential mechanisms for postnatal functional maturation of the striatum and their contribution to behavior.

\section{References}

Abrams J, Jones CA, Kirkpatrick P (2006) Ranolazine. Nat Rev Drug Discov 5:453-454.

Altman J, Sudarshan K (1975) Postnatal development of locomotion in the laboratory rat. Anim Behav 23:896-920.

Alzheimer C, Schwindt PC, Crill WE (1993) Postnatal development of a persistent $\mathrm{Na}+$ current in pyramidal neurons from rat sensorimotor cortex. J Neurophysiol 69:290-292.

Aosaki T, Graybiel AM, Kimura M (1994a) Effect of the nigrostriatal dopamine system on acquired neural responses in the striatum of behaving monkeys. Science 265:412-415.
Aosaki T, Tsubokawa H, Ishida A, Watanabe K, Graybiel AM, Kimura M (1994b) Responses of tonically active neurons in the primate's striatum undergo systematic changes during behavioral sensorimotor conditioning. J Neurosci 14:3969-3984.

Azam L, Winzer-Serhan UH, Chen Y, Leslie FM (2002) Expression of neuronal nicotinic acetylcholine receptor subunit mRNAs within midbrain dopamine neurons. J Comp Neurol 444:260-274.

Aznavour N, Mechawar N, Watkins KC, Descarries L (2003) Fine structural features of the acetylcholine innervation in the developing neostriatum of rat. J Comp Neurol 460:280-291.

Bäckman CM, Malik N, Zhang Y, Shan L, Grinberg A, Hoffer BJ, Westphal $\mathrm{H}$, Tomac AC (2006) Characterization of a mouse strain expressing Cre recombinase from the 3 ' untranslated region of the dopamine transporter locus. Genesis 44:383-390.

Bennett BD, Wilson CJ (1999) Spontaneous activity of neostriatal cholinergic interneurons in vitro. J Neurosci 19:5586-5596.

Bennett BD, Callaway JC, Wilson CJ (2000) Intrinsic membrane properties underlying spontaneous tonic firing in neostriatal cholinergic interneurons. J Neurosci 20:8493-8503.

BoSmith RE, Briggs I, Sturgess NC (1993) Inhibitory actions of ZENECA ZD7288 on whole-cell hyperpolarization activated inward current (If) in guinea-pig dissociated sinoatrial node cells. Br J Pharmacol 110:343-349.

Burt DK, Hungerford SM, Crowner ML, Baez LA (1982) Postnatal development of a cholinergic influence on neuroleptic-induced catalepsy. Pharmacol Biochem Behav 16:533-540.

Butcher LL, Hodge GK (1976) Postnatal development of acetylcholinesterase in the caudate-putamen nucleus and substantia nigra of rats. Brain Res 106:223-240.

Cachope R, Mateo Y, Mathur BN, Irving J, Wang HL, Morales M, Lovinger DM, Cheer JF (2012) Selective activation of cholinergic interneurons enhances accumbal phasic dopamine release: setting the tone for reward processing. Cell Rep 2:33-41.

Cazorla M, Shegda M, Ramesh B, Harrison NL, Kellendonk C (2012) Striatal D2 receptors regulate dendritic morphology of medium spiny neurons via Kir2 channels. J Neurosci 32:2398-2409.

Choi S, Lovinger DM (1997) Decreased probability of neurotransmitter release underlies striatal long-term depression and postnatal development of corticostriatal synapses. Proc Natl Acad Sci USA 94:2665-2670.

Choi SJ, Ma TC, Ding Y, Cheung T, Joshi N, Sulzer D, Mosharov EV, Kang UJ (2020) Alterations in the intrinsic properties of striatal cholinergic interneurons after dopamine lesion and chronic L-DOPA. Elife 9:e56920.

Connor JA, Stevens CF (1971) Prediction of repetitive firing behaviour from voltage clamp data on an isolated neurone soma. J Physiol 213:31-53.

Coyle JT, Campochiaro P (1976) Ontogenesis of dopaminergic-cholinergic interactions in the rat striatum: a neurochemical study. J Neurochem 27:673-678.

Coyle JT, Yamamura HI (1976) Neurochemical aspects of the ontogenesis of cholinergic neurons in the rat brain. Brain Res 118:429-440.

Dautan D, Huerta-Ocampo I, Witten IB, Deisseroth K, Bolam JP, Gerdjikov T T, Mena-Segovia J (2014) A major external source of cholinergic innervation of the striatum and nucleus accumbens originates in the brainstem. J Neurosci 34:4509-4618.

DiFiglia M (1987) Synaptic organization of cholinergic neurons in the monkey neostriatum. J Comp Neurol 255:245-258.

DiFiglia M, Pasik P, Pasik T (1976) A Golgi study of neuronal types in the neostriatum of monkeys. Brain Res 114:245-256.

Doremus-Fitzwater TL, Barreto M, Spear LP (2012) Age-related differences in impulsivity among adolescent and adult Sprague-Dawley rats. Behav Neurosci 126:735-741.

Exley R, Cragg SJ (2008) Presynaptic nicotinic receptors: a dynamic and diverse cholinergic filter of striatal dopamine neurotransmission. $\mathrm{Br} \mathrm{J}$ Pharmacol 153 [Suppl 1]:S283-S297.

Fibiger HC (1982) The organization and some projections of cholinergic neurons of the mammalian forebrain. Brain Res Rev 4:327-388.

Fitzgerald LW, Hannigan JH (1989) Cholinergic maturation and SCH 23390induced catalepsy in the male rat pup. Brain Res Dev Brain Res 47:147150.

Gerfen CR, Surmeier DJ (2011) Modulation of striatal projection systems by dopamine. Annu Rev Neurosci 34:441-466.

Gertler TS, Chan CS, Surmeier DJ (2008) Dichotomous anatomical properties of adult striatal medium spiny neurons. J Neurosci 28:10814-10824. 
Goldberg JA, Wilson CJ (2005) Control of spontaneous firing patterns by the selective coupling of calcium currents to calcium-activated potassium currents in striatal cholinergic interneurons. J Neurosci 25:10230-10238.

Goldberg JA, Reynolds JNJ (2011) Spontaneous firing and evoked pauses in the tonically active cholinergic interneurons of the striatum. Neuroscience 198:27-43.

Goldberg JA, Ding JB, Surmeier DJ (2012) Muscarinic modulation of striatal function and circuitry. Handb Exp Pharmacol :223-241.

Guevara CA, Matikainen-Ankney BA, Kezunovic N, LeClair K, Conway AP, Menard C, Flanigan ME, Pfau M, Russo SJ, Benson DL, Huntley GW (2020) LRRK2 mutation alters behavioral, synaptic, and nonsynaptic adaptations to acute social stress. J Neurophysiol 123:2382-2389.

Guyenet PG, Beaujouan JC, Glowinski J (1975) Ontogenesis of neostriatal cholinergic neurones in the rat and development of their sensitivity to neuroleptic drugs. Naunyn Schmiedebergs Arch Pharmacol 288:329-334.

Hall WG, Cramer CP, Blass EM (1977) Ontogeny of suckling in rats: transitions toward adult ingestion. J Comp Physiol Psychol 91:1141-1155.

Henderson Z (1981) Ultrastructure and acetylcholinesterase content of neurones forming connections between the striatum and substantia nigra of rat. J Comp Neurol 197:185-196.

Jing $M$, Zhang P, Wang G, Feng J, Mesik L, Zeng J, Jiang H, Wang S, Looby JC, Guagliardo NA, Langma LW, Lu J, Zuo Y, Talmage DA, Role LW, Barrett PQ, Zhang LI, Luo M, Song Y, Zhu JJ, et al. (2018) A genetically encoded fluorescent acetylcholine indicator for in vitro and in vivo studies. Nat Biotechnol 36:726-737.

Kawaguchi Y (1993) Physiological, morphological, and histochemical characterization of three classes of interneurons in rat neostriatum. J Neurosci 13:4908-4923.

Kemp JM, Powell TP (1971a) The structure of the caudate nucleus of the cat: light and electron microscopy. Philos Trans R Soc Lond B Biol Sci 262:383-401.

Kemp JM, Powell TP (1971b) The synaptic organization of the caudate nucleus. Philos Trans R Soc Lond B Biol Sci 262:403-412.

Khandelwal N, Cavalier S, Rybalchenko V, Kulkarni A, Anderson AG, Konopka G, Gibson JR (2021) FOXP1 negatively regulates intrinsic excitability in D2 striatal projection neurons by promoting inwardly rectifying and leak potassium currents. Mol Psychiatry. Advance online publication. Retrieved Jan 5, 2021. doi: 10.1038/s41380-020-00995-x.

Kimura H, McGeer PL, Peng F, McGeer EG (1980) Choline acetyltransferase-containing neurons in rodent brain demonstrated by immunohistochemistry. Science 208:1057-1059.

Kozorovitskiy Y, Saunders A, Johnson CA, Lowell BB, Sabatini BL (2012) Recurrent network activity drives striatal synaptogenesis. Nature 485:646-650.

Kozorovitskiy Y, Peixoto R, Wang W, Saunders A, Sabatini BL (2015) Neuromodulation of excitatory synaptogenesis in striatal development. Elife 4:e10111.

Krajeski RN, Macey-Dare A, van Heusden F, Ebrahimjee F, Ellender TJ (2019) Dynamic postnatal development of the cellular and circuit properties of striatal D1 and D2 spiny projection neurons. J Physiol 597:52655293.

Kuo HY, Liu F-C (2019) Synaptic wiring of corticostriatal circuits in basal ganglia: insights into the pathogenesis of neuropsychiatric disorders. eNeuro 6:ENEURO.0076-19.2019.

Le Novère N, Zoli M, Changeux JP (1996) Neuronal nicotinic receptor alpha 6 subunit mRNA is selectively concentrated in catecholaminergic nuclei of the rat brain. Eur J Neurosci 8:2428-2439.

Liao WL, Tsai HC, Wang HF, Chang J, Lu KM, Wu HL, Lee YC, Tsai TF, Takahashi H, Wagner M, Ghyselinck NB, Chambon P, Liu FC (2008) Modular patterning of structure and function of the striatum by retinoid receptor signaling. Proc Natl Acad Sci USA 105:6765-6770.

Lieberman OJ, Choi SJ, Kanter E, Saverchenko A, Frier MD, Fiore GM, Wu M, Kondapalli J, Zampese E, Surmeier DJ, Sulzer D, Mosharov EV (2017) $\alpha$-Synuclein-dependent calcium entry underlies differential sensitivity of cultured SN and VTA dopaminergic neurons to a parkinsonian neurotoxin. eNeuro 4:ENEURO.0167-17.2017.

Lieberman OJ, McGuirt AF, Mosharov EV, Pigulevskiy I, Hobson BD, Choi S, Frier MD, Santini E, Borgkvist A, Sulzer D (2018) Dopamine triggers the maturation of striatal spiny projection neuron excitability during a critical period. Neuron 99:540-554.e4.

Lieberman OJ, Cartocci V, Pigulevskiy I, Molinari M, Carbonell J, Broseta MB, Post MR, Sulzer D, Borgkvist A, Santini E (2020) mTOR suppresses macroautophagy during striatal postnatal development and is hyperactive in mouse models of autism spectrum disorders. Front Cell Neurosci 14:70.

Lunko O, Isaev D, Maximyuk O, Ivanchick G, Sydorenko V, Krishtal O, Isaeva E (2014) Persistent sodium current properties in hippocampal CA1 pyramidal neurons of young and adult rats. Neurosci Lett 559:30-33.

Mainen ZF, Sejnowski TJ (1996) Influence of dendritic structure on firing pattern in model neocortical neurons. Nature 382:363-366.

Matsumoto N, Minamimoto T, Graybiel AM, Kimura M (2001) Neurons in the thalamic CM-Pf complex supply striatal neurons with information about behaviorally significant sensory events. J Neurophysiol 85:960-976.

Maurice N, Mercer J, Chan CS, Hernandez-Lopez S, Held J, Tkatch T, Surmeier DJ (2004) D2 dopamine receptor-mediated modulation of voltage-dependent $\mathrm{Na}+$ channels reduces autonomous activity in striatal cholinergic interneurons. J Neurosci 24:10289-10301.

Mohebi A, Pettibone JR, Hamid AA, Wong J-MT, Vinson LT, Patriarchi T, Tian L, Kennedy RT, Berke JD (2019) Dissociable dopamine dynamics for learning and motivation. Nature 570:65-70.

Mosharov EV (2008) Analysis of single-vesicle exocytotic events recorded by amperometry. Methods Mol Biol 440:315-327.

Murrin LC, Ferrer JR (1984) Ontogeny of the rat striatum: correspondence of dopamine terminals, opiate receptors and acetylcholinesterase. Neurosci Lett 47:155-160.

Oldenburg IA, Ding JB (2011) Cholinergic modulation of synaptic integration and dendritic excitability in the striatum. Curr Opin Neurobiol 21:425-432.

Peixoto RT, Wang W, Croney DM, Kozorovitskiy Y, Sabatini BL (2016) Early hyperactivity and precocious maturation of corticostriatal circuits in Shank3B(-/-) mice. Nat Neurosci 19:716-724.

Peixoto RT, Chantranupong L, Hakim R, Levasseur J, Wang W, Merchant T, Gorman K, Budnik B, Sabatini BL (2019) Abnormal striatal development underlies the early onset of behavioral deficits in Shank3B-/- mice. Cell Rep 29:2016-2027.e4.

Phelps PE, Brady DR, Vaughn JE (1989) The generation and differentiation of cholinergic neurons in rat caudate-putamen. Brain Res Dev Brain Res 46:47-60.

Plotkin JL, Wu N, Chesselet M-F, Levine MS (2005) Functional and molecular development of striatal fast-spiking GABAergic interneurons and their cortical inputs. Eur J Neurosci 22:1097-1108.

Reynolds JNJ, Hyland BI, Wickens JR (2004) Modulation of an afterhyperpolarization by the substantia nigra induces pauses in the tonic firing of striatal cholinergic interneurons. J Neurosci 24:9870-9877.

Rice ME, Cragg SJ (2004) Nicotine amplifies reward-related dopamine signals in striatum. Nat Neurosci 7:583-584.

Robinson RB, Siegelbaum SA (2003) Hyperpolarization-activated cation currents: from molecules to physiological function. Annu Rev Physiol 65:453-480.

Sawa A, Stavinoha WB (1987) Heterogeneity of postnatal development of ACh levels in brain regions of the mouse. Dev Brain Res 34:151155.

Shaywitz BA, Gordon JW, Klopper JH, Zelterman DA, Irvine J (1979) Ontogenesis of spontaneous activity and habituation of activity in the rat pup. Dev Psychobiol 12:359-367.

Song DD, Harlan RE (1994) Genesis and migration patterns of neurons forming the patch and matrix compartments of the rat striatum. Brain Res Dev Brain Res 83:233-245.

Song WJ, Tkatch T, Baranauskas G, Ichinohe N, Kitai ST, Surmeier DJ (1998) Somatodendritic depolarization-activated potassium currents in rat neostriatal cholinergic interneurons are predominantly of the A type and attributable to coexpression of Kv4.2 and Kv4.1 subunits. J Neurosci 18:3124-3137.

Spear LP (2013) Adolescent neurodevelopment. J Adolesc Health 52:S7-S13.

Sturman DA, Moghaddam B (2012) Striatum processes reward differently in adolescents versus adults. Proc Natl Acad Sci USA 109:1719-1724.

Sturman DA, Mandell DR, Moghaddam B (2010) Adolescents exhibit behavioral differences from adults during instrumental learning and extinction. Behav Neurosci 124:16-25.

Sulzer D, Cragg SJ, Rice ME (2016) Striatal dopamine neurotransmission: regulation of release and uptake. Basal Ganglia 6:123-148.

Surmeier DJ, Stefani A, Foehring RC, Kitai ST (1991) Developmental regulation of a slowly-inactivating potassium conductance in rat neostriatal neurons. Neurosci Lett 122:41-46. 
Tanimura A, Lim SAO, Aceves B. J d J, Goldberg JA, Surmeier DJ (2016) Cholinergic interneurons amplify corticostriatal synaptic responses in the Q175 model of Huntington's disease. Front Syst Neurosci 10:102.

Tepper JM, Sharpe NA, Koós TZ, Trent F (1998) Postnatal development of the rat neostriatum: electrophysiological, light- and electron-microscopic studies. Dev Neurosci 20:125-145.

Threlfell S, Lalic T, Platt NJ, Jennings KA, Deisseroth K, Cragg SJ (2012) Striatal dopamine release is triggered by synchronized activity in cholinergic interneurons. Neuron 75:58-64.

Tubert C, Taravini IRE, Flores-Barrera E, Sánchez GM, Prost MA, Avale ME, Tseng KY, Rela L, Murer MG (2016) Decrease of a current mediated by kv1.3 channels causes striatal cholinergic interneuron hyperexcitability in experimental parkinsonism. Cell Rep 16:2749-2762.

van der Kooy D, Fishell G (1987) Neuronal birthdate underlies the development of striatal compartments. Brain Res 401:155-161.

Westerga J, Gramsbergen A (1990) The development of locomotion in the rat. Brain Res Dev Brain Res 57:163-174.
Wilson CJ (2005) The mechanism of intrinsic amplification of hyperpolarizations and spontaneous bursting in striatal cholinergic interneurons. Neuron 45:575-585

Wilson CJ, Goldberg JA (2006) Origin of the slow afterhyperpolarization and slow rhythmic bursting in striatal cholinergic interneurons. J Neurophysiol 95:196-204.

Wilson CJ, Chang HT, Kitai ST (1990) Firing patterns and synaptic potentials of identified giant aspiny interneurons in the rat neostriatum. J Neurosci 10:508-519.

Zariwala HA, Borghuis BG, Hoogland TM, Madisen L, Tian L, De Zeeuw CI, Zeng H, Looger LL, Svoboda K, Chen TW (2012) A Cre-dependent GCaMP3 reporter mouse for neuronal imaging in vivo. J Neurosci 32:31313141.

Zhang H, Sulzer D (2004) Frequency-dependent modulation of dopamine release by nicotine. Nat Neurosci 7:581-582.

Zhou FM, Liang Y, Dani JA (2001) Endogenous nicotinic cholinergic activity regulates dopamine release in the striatum. Nat Neurosci 4:1224-1229.

Zoli M, Moretti M, Zanardi A, McIntosh JM, Clementi F, Gotti C (2002) Identification of the nicotinic receptor subtypes expressed on dopaminergic terminals in the rat striatum. J Neurosci 22:8785-8789. 